\title{
The effect of lateral variations in Earth structure on Last Interglacial sea level
}

\author{
Jacqueline Austermann*,1, Mark J. Hoggard $^{1,2,3}$, Konstantin Latychev ${ }^{1,2}$, Fred D. Richards ${ }^{4}$, \& Jerry X. \\ Mitrovica $^{2}$
}

1. Lamont-Doherty Earth Observatory, Columbia University, New York, USA.

2. Department of Earth \& Planetary Sciences, Harvard University, Cambridge, USA.

3. Research School of Earth Sciences, Australian National University, Canberra, Australia.

4. Department of Earth Science and Engineering, Imperial College London, London, UK

*jackya@1deo.columbia.edu

\begin{abstract}
It is generally agreed that the Last Interglacial (LIG; $130-115 \mathrm{ka}$ ) was a time when global average temperatures and global mean sea level were higher than they are today. However, the exact timing, magnitude, and spatial pattern of ice melt is much debated. One difficulty in extracting past global mean sea level from local observations is that their elevations need to be corrected for glacial isostatic adjustment (GIA), which requires knowledge of Earth's internal viscoelastic structure. While this structure is generally assumed to be radially symmetric, evidence from seismology, geodynamics, and mineral physics indicates that large lateral variations in viscosity exist within the mantle. In this study, we construct a new model of Earth's internal structure by converting shear wave speed into viscosity using parameterisations from mineral physics experiments and geodynamical constraints on Earth's thermal structure. We use this 3D Earth structure, which includes both variations in lithospheric thickness and lateral variations in viscosity, to calculate the first 3D GIA prediction for LIG sea level. We find that the difference between predictions with and without lateral Earth structure can be meters to 10 s of meters in the near field of former ice sheets, and up to a few meters in their far field. We demonstrate how forebulge dynamics and continental levering are affected by laterally varying Earth structure, with a particular focus on those sites with prominent LIG sea level records. Results from four 3D GIA calculations show that accounting for lateral structure can act to increase local sea level by up to $\sim 1.5 \mathrm{~m}$ at the Seychelles and minimally decrease it in Western Australia. We acknowledge that this result is only based on a few simulations, but if robust, this shift brings estimates of global mean sea level from these two sites into closer agreement with each other. We further demonstrate that simulations with a suitable radial viscosity profile can be used to locally approximate the 3D GIA result, but that these radial profiles cannot be found by simply averaging viscosity below the sea level indicator site.
\end{abstract}

\section{Keywords:}

Composition and structure of the mantle, Mantle processes, Sea level change, Rheology: mantle, Dynamics of lithosphere and mantle 


\section{Introduction}

The Last Interglacial (LIG; $\sim 130-115 \mathrm{ka}$ ) is a time in Earth's history during which global average temperatures were $1-2^{\circ} \mathrm{C}$ warmer than pre-industrial values (Dutton et al., 2015a). As such, it has been used as a testing ground to study how ice sheets and sea level respond to past and possibly future warming (DeConto \& Pollard, 2016; Fischer et al., 2018). Reconstructions of global mean sea level (GMSL) during the LIG are based on sea-level indicators, such as fossil corals, that constrain the local elevation of sea level at their time of formation (Rovere et al., 2016). Once locally reconstructed, this elevation has to be corrected for processes that cause a deviation between local sea level and the GMSL. One of these processes is glacial isostatic adjustment (GIA), which is the response of Earth's solid surface, gravity field, and rotation axis to changes in ice and ocean mass. GIA is an important contributor to interglacial sea-level change, even far away from major ice sheets (e.g. Mitrovica \& Milne, 2002; Lambeck et al., 2012). In addition to GIA, other processes such as earthquakes, crustal deformation, sediment loading, and dynamic topography can further deform Earth's surface and cause local sea-level change (Briggs et al., 2014; Austermann et al., 2017; Pico, 2019; Stephenson et al., 2019).

Estimates of peak GMSL during the LIG, whether based on records from individual sites (Dutton et al., 2015b; O’Leary et al., 2013) or by combining data from multiple locations into a statistical framework (Kopp et al., 2009), are generally between $6-9 \mathrm{~m}$. However, some recent work suggests that this range may be overestimating GMSL during the LIG (Dyer et al., in press.; Clark et al., 2020). In general, significant debate continues about both the magnitude of excess melt (relative to present day) and its timing: data from Western Australia indicate that GMSL exceeded present-day values by a few meters early in the LIG, followed by a GMSL rise up to $9 \mathrm{~m}$ towards the end of the LIG (O'Leary et al., 2013). This reconstruction is in disagreement with estimates obtained from the Seychelles, which indicate that high GMSL was attained early in the LIG and continued to slowly increase, with possible intermittent sea level drops (Dutton et al., 2015b; Vyverberg et al., 2018). While constraints from late LIG sea level are absent in the Seychelles, they are present in Xcaret, Mexico - where sea level has been argued to undergo a step increase around $121 \mathrm{ka}$ (Blanchon et al., 2009) and Mallorca, where speleothem records indicate constant or slightly falling GMSL throughout the LIG (Polyak et al., 2018). A global compilation of data indicates an oscillation in sea level with a highstand both early and late (Kopp et al., 2009), however this result is not strongly supported by either proximal ice records or ice sheet dynamics (Barlow et al., 2018).

Ongoing disagreement regarding the magnitude, timing, and spatial distribution of LIG melt raises the 
possibility that complexities associated with the GIA correction may be responsible for some of these differences. As noted above, each local sea-level estimate needs to be corrected for GIA to infer GMSL. The GIA correction requires both an ice history and a viscoelastic structure for Earth's interior as input, both of which are underconstrained. Uncertainties associated with the ice history can change the GIA correction by several meters during the LIG (Dendy et al., 2017; Rohling et al., 2017; Lambeck et al., 2012). In regard to Earth's viscoelastic structure, previous studies of LIG sea level have all assumed that Earth's viscosity varies purely as a function of depth. However, based on evidence from seismic tomography, mineral physics, and geodynamics, it is expected that significant lateral variations exist in both Earth's viscosity and lithospheric structure (e.g. Dannberg et al., 2017; Priestley et al., 2018). Indeed, these lateral variations are important for understanding the impact of GIA on sea level during the last deglaciation (Austermann et al., 2013; Li et al., 2018; Kuchar et al., 2019) and affect the pattern of present-day deformation across Antarctica (Nield et al., 2018; Gomez et al., 2018).

In this study, we focus on investigating how lateral variations in Earth structure affect sea level during the LIG. We generate a new model of lateral Earth structure that is based on seismic tomography. In contrast to previous work, which adopts a pre-determined scaling from shear wave speed into viscosity for the upper mantle (Austermann et al., 2013; Gomez et al., 2018; Li et al., 2018), we invert laboratory-based parameterisations for material properties using a suite of independent constraints on mantle structure (Richards et al., 2020). We pair this Earth model with an ice history to predict the effect of lateral viscosity variations on sea level at key sites, and provide physical insights into the GIA changes predicted both in the near and far field (i.e. close and distant to the ice sheet). Given the computational expense of such calculations, we are limited to performing a relatively small set of exploratory simulations, but these nevertheless provide a first estimate of the potential magnitude and geometry of the LIG GIA signal associated with realistic departures from radial mantle viscosity profiles. While this work is focused on the LIG, insights on the physical mechanisms hold for any interglacial period and are therefore also relevant to earlier interglacials (e.g., MIS 11) and the late Holocene. We also investigate how well the GIA signal obtained when including lateral variability in Earth structure can, at a given location, be accurately represented by a GIA model with a purely radial Earth structure. Lastly, we compare our results to LIG sea level records at key sites to consider the extent to which lateral Earth structure and the associated GIA prediction might impact estimates of GMSL over the LIG. 


\section{Methods and Data}

\subsection{GIA numerical model}

To investigate how GIA causes spatially varying sea level over the LIG, we use a finite volume-based approach to solve for radial displacement of the solid Earth, its change in gravity field, and rotation axis in response to an evolving ice and ocean load (Latychev et al., 2005). The numerical approach incorporates lateral variations in Earth structure and calculates the resulting gravitationally self-consistent sea-level change, while accurately accounting for shoreline migration (Mitrovica \& Milne, 2003). This computational model is well established, having been used in many previous studies (e.g. Austermann et al., 2013; Kuchar et al., 2019; Gomez et al., 2018; Goldberg et al., 2016). GIA calculations described here for radially symmetric Earth structure are performed using both the finite volume approach described above and the pseudo-spectral approach described in Kendall et al. (2005).

\subsection{Ice reconstruction}

The ice reconstruction we adopt is based on a combination of several published studies in order to obtain satisfactory fits to multiple independent datasets (Fig. 1). From the present day back to 26 ka, we use the deglacial ice sheet reconstruction ICE-6G (Peltier et al., 2015). For the preceding glaciation, we use the reconstructions by Pico et al. (2017) and Creveling et al. (2017), which are more consistent with sea-level observations from these time periods. To isolate the GIA contribution to sea level during the LIG, we assume present-day ice geometry from 128 - $117 \mathrm{ka}$. Any excess ice melt beyond the present-day level will, of course, produce an additional geographically varying sea-level fingerprint (Hay et al., 2014). The timing and melt geometry of the penultimate deglaciation has been widely debated, with estimates including a smaller (Rohling et al., 2017) or larger (Shakun et al., 2015) overall ice volume compared to the last deglaciation; a deglaciation that commenced early (around $140 \mathrm{ka}$; Thomas et al., 2009) or late (closer to $135 \mathrm{ka}$; Waelbroeck et al., 2002); and an ice distribution characterised by a slightly (Lambeck et al., 2006) or significantly (Colleoni et al., 2016) larger Fennoscandian ice sheet relative to LGM. The ice geometry and timing of melt across the penultimate deglaciation will significantly affect GIA during the LIG and has been explored in detail elsewhere (Dendy et al., 2017; Rohling et al., 2017). Here, we adopt a representative ice history that has a total ice volume at the

penultimate glacial maximum (PGM) that is similar to the last glacial maximum (LGM; consistent with oxygen isotope estimates; Waelbroeck et al., 2002), a slightly slower deglaciation than during the last deglaciation (in 

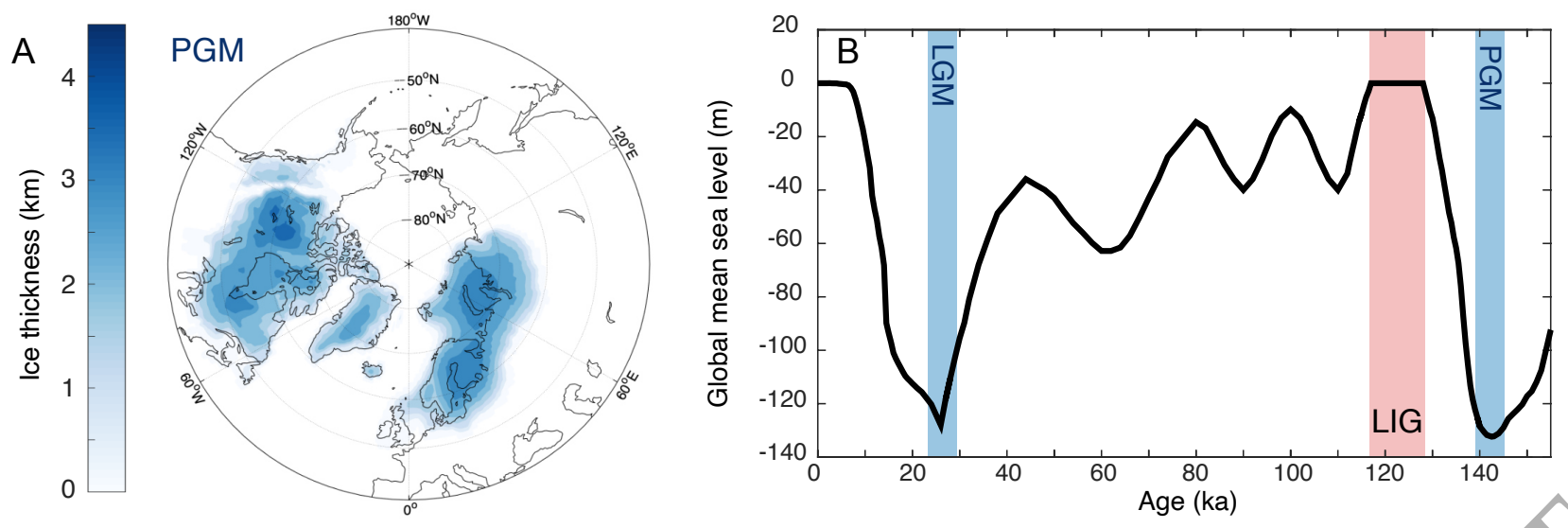

Figure 1: Ice model reconstruction. A) Distribution of northern hemisphere ice during the penultimate glacial maximum (PGM) used in our model. The Fennoscandian ice sheet is based on Lambeck et al. (2006). B) Global mean sea level with respect to present day over the course of the model. Vertical coloured bars indicate timings of the last glacial maximum (LGM), Last Interglacial (LIG), and penultimate glacial maximum.

line with U-Th dated corals from Tahiti; Thomas et al., 2009), and an ice distribution characterised by a larger Fennoscandian ice sheet, following Lambeck et al. (2006), and in turn smaller Laurentide ice sheet (Fig. 1). Our calculations start at $150 \mathrm{ka}$ and continue until the present day.

\subsection{Elastic Earth structure}

To model the instantaneous elastic deformation of the solid Earth in response to evolving ice loads, we require estimates of the bulk and shear moduli of the mantle. We adopt the radially symmetric model STW105 (Kustowski et al., 2008), which uses more data and án improved inversion scheme and crustal correction compared to earlier studies such as PREM (Dziewonski \& Anderson, 1981). We emphasise that the choice of the elastic structure has only a minimal effect on our results (i.e. on the order of centimetres during the LIG). While elastic moduli are known to vary laterally, these perturbations are considerably smaller than those in viscosity and do not play a first-order role in the GIA response. We therefore maintain a radially symmetric elastic structure and only investigate the effect of lateral viscosity variations in this study.

\subsection{Viscous Earth structure including lithospheric thickness variations}

The mantle convects with a time-dependent planform that evolves on million-year timescales and introduces significant lateral temperature heterogeneity (Turcotte \& Schubert, 2002). Laboratory experiments on the deformation of mantle rocks show that their viscosity is strongly dependent on temperature, and it has therefore 
long been known that significant lateral variations in viscosity occur within the mantle (Cathles, 1975; Ranalli, 1995). The velocity of seismic waves is also sensitive to mantle temperature and rheology, and seismic tomography is therefore our most direct tool for imaging mantle structure (Bullen, 1975).

Seismic velocities are traditionally converted into temperature and then viscosity using a combination of physical and phenomenological laws (e.g. thermal expansion, an Arrhenius relationship to describe the temperature dependence of viscosity) and material properties that have been derived from laboratory experiments. Here, we construct a mantle viscosity structure that relies on these same conversion relationships, including an up-to-date treatment of anelasticity at seismic frequencies that is detailed below. As with previous studies, uncertainties in the appropriate material properties, the rheological deformation mechanism responsible for accommodating GIA motions, and variations in measured seismic velocity structure between different tomography models all introduce uncertainty into the resulting viscosity structure. In contrast to other studies, however, we leverage additional information on the thermal and rheological state of the upper mantle to optimise the selection of appropriate material properties. This approach substantially reduces uncertainties in inferred mantle viscosity structure, which is demonstrated and discussed in Section 4.1.

\subsubsection{Viscosity above the transition zone and lithospheric thickness}

When a polycrystalline viscoelastic material - such as the mantle - is cold, deformation associated with the passage of acoustic energy is elastic, yielding a linear dependence of shear-wave velocity $\left(\mathrm{V}_{S}\right)$ on temperature referred to as the anharmonic velocity. As temperature increases, however, anelastic deformation (a special case of fully recoverable viscoelastic deformation) also begins to occur due to the presence of point defects, dislocations, and grain boundaries. This additional process results in a non-linear relationship between $\mathrm{V}_{S}$ and temperature and is particularly important to account for when inferring viscosity in high-temperature regions (Karato, 1993; Wu et al., 2012). Anelastic behaviour has been extensively studied in laboratory experiments on silicates and organic analogues of mantle rocks, revealing that the strength of the anelastic regime varies with both the frequency of seismic waves and as a function of material properties, such as melting temperature and grain size (Sundberg \& Cooper, 2010; McCarthy et al., 2011; Faul \& Jackson, 2015). Several studies have attempted to parameterise these complex dependencies and have been regularly updated as forced oscillation and creep experiments in the laboratory have been pushed towards increasingly realistic frequencies, pressures, temperatures, grain sizes, and strain rates (Jackson \& Faul, 2010; Takei, 2017).

In this study, we map $\mathrm{V}_{S}$ into temperature and viscosity in the upper $400 \mathrm{~km}$ of the mantle using the param- 
eterisation of Yamauchi \& Takei (2016), which has been developed through forced oscillation experiments on borneol. The parameterisation accounts for the effects of anelasticity in pre-melt conditions, when temperature ( $T$ ) exceeds $\sim 90 \%$ of the melting temperature ( $T_{m}$; both defined in Kelvin). These conditions most often occur in regions of the asthenosphere that underlie thin lithosphere, such as beneath West Antarctica, which is a site that experiences significant ice mass changes over the glacial cycle. Specific details on the representation of anelasticity are provided in Appendix A. To summarise, seismic velocity and attenuation are self-consistently tied to temperature and steady-state diffusion creep viscosity via a system of coupled equations that depend on seven material properties (including the activation energy, $E_{a}$, which controls the dependence of viscosity on temperature through an Arrhenius relationship). Here, we assume that temperature is the dominant cause of seismic velocity variations and that grain size and composition play only a second-order role. The equations that are being used in this study are given by Equations (3) - (17) of Richards et al. (2020).

The standard approach is to adopt material properties and their associated uncertainties that are appropriate for upper mantle rocks (typically olivine) and have been obtained from laboratory experiments (e.g. Kaufmann et al., 2005; van der Wal et al., 2010; Li et al., 2018). Here, rather than fixing these properties using an assumed mineralogy, we take advantage of an inverse calibration scheme outlined in Richards et al. (2020) that considerably reduces uncertainty in inferred mantle structure (see Section 4.1). The philosophy behind the approach is that certain physical properties of the Earth are 'known', including the typical thermal structure of oceanic lithosphere, the average adiabatic temperature profile within the convecting mantle, the attenuation structure of the upper mantle beneath old oceanic lithosphere, and the mean diffusion creep viscosity of the upper mantle from studies of GIA. Any model of upper mantle temperature and viscosity structure inferred from shear wave velocities should be compatible with these constraints, and we therefore restrict ourselves to a subset of material properties that also satisfy these physical characteristics.

To generate the constraints, we first stack shear-wave velocities from the tomography model (described below) as a function of depth and oceanic age. Temperature contours from the Richards et al. (2018) plate cooling model are subsequently overlain and $\mathrm{V}_{S}-T$ tie points at depths of $75 \mathrm{~km}, 100 \mathrm{~km}$, and $125 \mathrm{~km}$ are extracted. A second set of deeper tie points is generated by assuming that the average value of $\mathrm{V}_{S}$ as a function of depth oyer the $225-400 \mathrm{~km}$ range should yield a temperature that is consistent with the $1333^{\circ} \mathrm{C}$ adiabat. A third constraint is obtained by overlaying the observed attenuation structure at depths of $150-400 \mathrm{~km}$ beneath > 100 Ma seafloor from the QRFSI12 model of Dalton et al. (2009) on the equivalent $\mathrm{V}_{S}$ stack, in order to generate a set of $\mathrm{V}_{S^{-}} Q^{-1}$ tie points as a function of depth. Finally, we require that the mean diffusion 
creep viscosity from 225 - $400 \mathrm{~km}$ depth be equivalent to the average upper mantle value of $3 \times 10^{20} \mathrm{~Pa} \mathrm{~s}$ that has been obtained from previous studies of GIA (Lau et al., 2016). We calculate a range of predicted temperature, attenuation, and viscosity maps by varying the seven material properties and comparing the results to the calibration targets described above. Misfit is optimised by iteratively updating the material properties. To reduce the likelihood of locating local minima in the inversion, we use a two-step minimisation algorithm consisting of an initial, relatively coarse parameter sweep followed by Powell's conjugate gradient algorithm. Further details on this calibration scheme can be found in Richards et al. (2020).

Here, we use the SL2013sv tomography model, which has global coverage in the upper mantle, and patch in the SL2013NA regional update in North America that takes advantage of the dense station coverage afforded by the USArray seismic network (Schaeffer \& Lebedev, 2013, 2014). We have chosen this model for two reasons. First, it has high horizontal resolution ( $280 \mathrm{~km}$ horizontal node spacing) and is constructed from both body waves and a large quantity of surface wave data (including higher modes), which are particularly sensitive to velocity structure in the upper $\sim 350 \mathrm{~km}$ of the mantle. Secondly, density and temperature fields derived from this model have been shown to correlate well with independent geophysical and geological observations including gravity anomalies, residual topography, continental geotherms, and mineral deposits (Steinberger, 2016; Hoggard et al., 2017, 2020). The anelastic calibration scheme yields optimal material properties of 74.7 GPa for the reference shear modulus (with $1 \sigma$ uncertainties of approximately $3 \%$ ). Its dependence on temperature is $-16.1 \mathrm{MPa}{ }^{\circ} \mathrm{C}^{-1}(\sim 12 \%)$ and on pressure is 2.56 (dimensionless, $\sim 7 \%$ ), respectively. The reference diffusion creep viscosity is $2.51 \times 10^{21} \mathrm{~Pa} \mathrm{~s}(\sim 8 \%)$, and its dependence on temperature and pressure are controlled by an activation energy of $304 \mathrm{~kJ} \mathrm{~mol}^{-1}\left( \pm 250 \mathrm{~kJ} \mathrm{~mol}^{-1}\right)$ and activation volume of $3.0 \mathrm{~cm}^{3} \mathrm{~mol}^{-1}$ $\left( \pm 6.0 \mathrm{~cm}^{3} \mathrm{~mol}^{-1}\right)$. All uncertainties are $1 \sigma$. We note that a negative activation volume would imply that the sensitivity of viscosity to temperature may decrease with depth, which has previously been suggested for mantle mineral assemblages when self-diffusion of certain ions (such as $\mathrm{Si}$ and $\mathrm{O}$ ) becomes rate-limiting (Fei et al., 2018; Jain et al., 2019). The solidus gradient is $0.946{ }^{\circ} \mathrm{C} \mathrm{km}^{-1}(\sim 25 \%)$. The resulting scaling relationship between shear wave velocity and lateral viscosity perturbations is shown in Fig. 2. Throughout the manuscript we define lateral viscosity perturbations as $\log _{10} \frac{\eta_{1}}{\eta_{0}}$. The effect of accounting for anelastic effects in this manner is to increase viscosities by between 1 and 1.5 orders of magnitude in the slowest $V_{S}$, lowest-viscosity locations, in comparison to a purely anharmonic conversion (Fig. 2 E). Viscosities are unaffected in faster velocity regions where temperatures are colder (i.e. $T<0.9 T_{m}$ ).

Lithospheric thickness is identified using the depth of the $1175^{\circ} \mathrm{C}$ isothermal surface, which has an average 

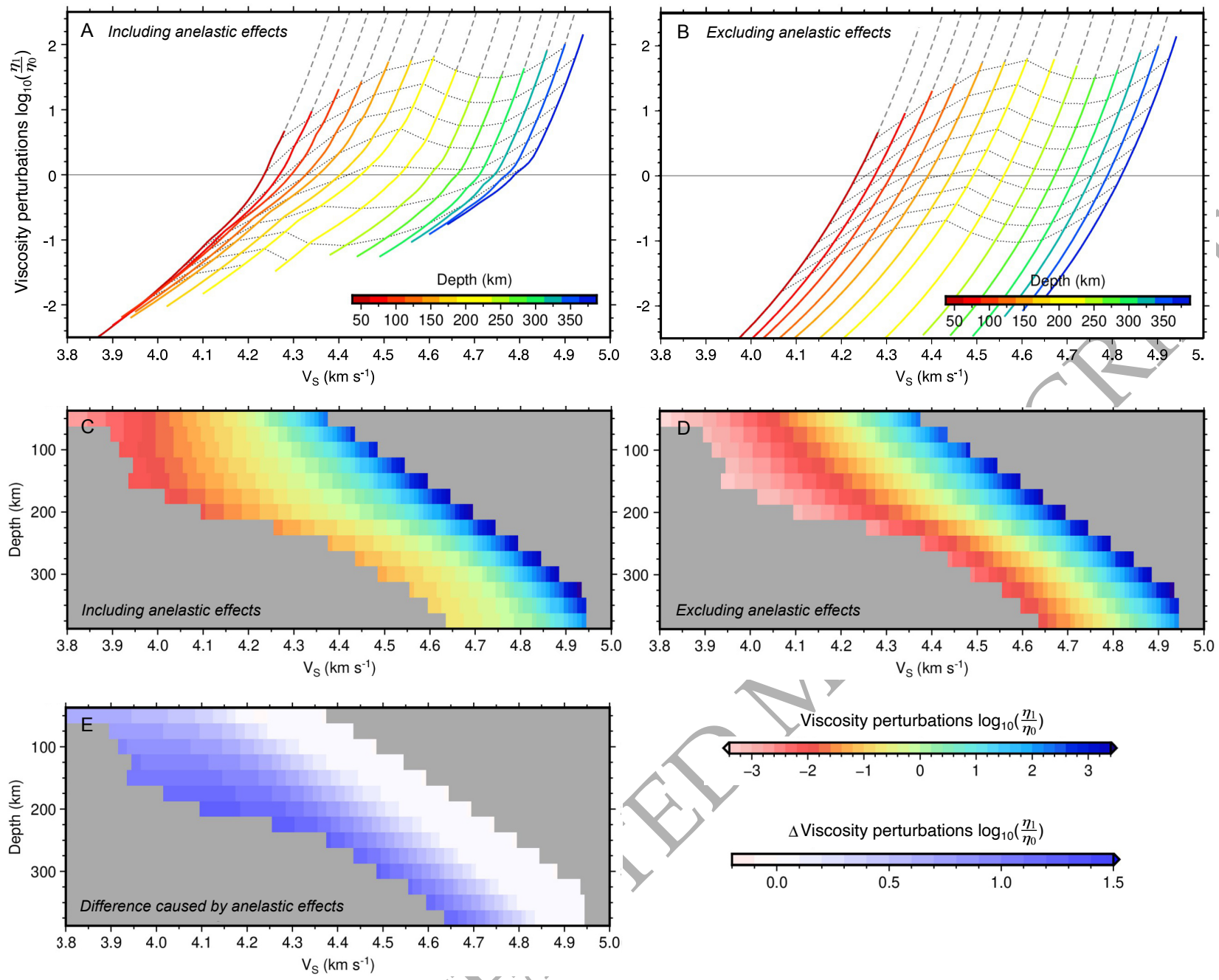

Figure 2: Conversion of shear wave speed to viscosity perturbations. A) Calibrated relationship between shear wave velocity $\left(V_{S}\right)$ and lateral viscosity perturbations as a function of depth for our calibrated upper-mantle model of anelasticity at seismic frequencies (Schaeffer \& Lebedev, 2013, 2014; Yamauchi \& Takei, 2016; Richards et al., 2020). Coloured lines transition to dashed grey at the lithosphere-asthenosphere boundary (i.e. $1175^{\circ} \mathrm{C}$ ); black dotted lines are isothermal contours from $1200^{\circ} \mathrm{C}$ to $1600^{\circ} \mathrm{C}$ at $50^{\circ} \mathrm{C}$ increments. B) Same if anelastic effects are excluded. C, D) Same values as in A and B, respectively, but plotted as $V_{S}$ versus depth and coloured by viscosity perturbations. E) Difference between $\mathrm{C}$ and D, illustrating that including anelastic effects primarily acts to increase the inferred viscosity at slow shear wave velocities. Throughout this study, we include anelastic effects and use the conversion shown in panels A and C. 
global value of $\sim 100 \mathrm{~km}$ and varies from $\sim 300 \mathrm{~km}$ in cratonic regions to $<25 \mathrm{~km}$ in sites of active rifting and at mid-oceanic spreading centres (Fig. 3A, Hoggard et al., 2020). This specific isotherm is chosen because it coincides with seismological evidence for the depth of the lithosphere-asthenosphere boundary in oceanic regions (Richards et al., 2018). At $100 \mathrm{~km}$ depth, a temperature of $1175^{\circ} \mathrm{C}$ corresponds to a diffusion creep viscosity of $4.5 \times 10^{22} \mathrm{~Pa}$ s in our anelasticity parameterisation, which yields a characteristic Maxwell time of $\sim 20 \mathrm{kyr}$. We therefore consider this boundary an adequate representation of the transition between asthenospheric material that undergoes viscoelastic deformation during the simulation, and lithospheric material that only deforms elastically. It has been suggested that lithospheric thickness on GIA timescales appears thinner than inferred over the seismic cycle due to the onset of viscous or transient deformation (Watts et al., 2013; Lau et al., 2020). We therefore perform an additional sensitivity test where lithospheric thickness is reduced everywhere by $20 \%$ (i.e., $80 \mathrm{~km}$ global average).

\subsubsection{Viscosity within and beneath the transition zone}

Deeper than $400 \mathrm{~km}$, the sensitivity of surface waves to velocity structure drops significantly, the dominant mantle mineralogy switches from olivine to wadsleyite, and the number of independent constraints on mantle properties is considerably more limited. For these reasons, we use a different approach to estimate viscosity perturbations below $400 \mathrm{~km}$ depths. For the tomography model, we take the whole mantle SEMUCB-WM1 model, which is constructed using a combination of body and surface wave data and uses a sophisticated hybrid approach to numerically simulate wavefield propagation and invert waveforms for shear wave-velocity structure (French \& Romanowicz, 2014). We linearly blend the upper and lower shear wave model over the $300-400 \mathrm{~km}$ depth range.

To generate lower mantle viscosity perturbations, we first convert $\mathrm{V}_{S}$ into temperature using the Perple_X Gibbs free-energy minimisation software of Connolly (2005) and the thermodynamic database of Stixrude \& Lithgow-Bertelloni (2011). Assuming a pyrolitic composition, the mineralogical make-up is estimated as a function of pressure and temperature, yielding predictions of the elastic moduli and density that can be converted into anharmonic velocity. At a given depth and for an individual mineral assemblage, these material properties exhibit an approximátely linear dependence on temperature, resulting in a unique conversion from anharmonic velocity into temperature. In the vicinity of phase transitions, however, a discontinuity occurs that can render this conversion non-unique. To avoid this issue, at each depth, we first linearise the temperature-dependence

of the density and elastic moduli over a temperature window that extends $\pm 500^{\circ} \mathrm{C}$ around a quasi-steady state 
geotherm obtained from mantle convection simulations (Supplementary Material; Schuberth \& Bunge, 2009). The anharmonic velocity as a function of pressure and temperature is subsequently corrected for anelastic effects using the Q5 radial attenuation profile, equations 1 \& 2 of Cammarano et al. (2003), and a mantle solidus from Andrault et al. (2011). To ensure that we obtain a self-consistent mantle geotherm from the tomography model, we extract the $\mathrm{V}_{S}$ variation over the $\pm 500^{\circ} \mathrm{C}$ temperature window and pin the absolute $\mathrm{V}_{S}$ at the geotherm temperature to the average $\mathrm{V}_{S}$ of the tomography model at this depth. Thus lateral $\mathrm{V}_{S}$ variations at any depth are mapped into temperature variations around the average geotherm. Finally, these temperature variations are converted into viscosity perturbations using a radial activation enthalpy profile constructed from our upper mantle result extended down to $660 \mathrm{~km}$, followed by the lower mantle profile of Steinberger \& Calderwood (2006).

\subsubsection{Resulting viscosity structure}

Our resulting lithospheric thickness and viscosity perturbations at specific depths are shown in Fig. 3 and are provided as supplementary material. As expected, thick lithosphere aligns with cratonic regions and it thins towards mid-ocean ridges (Fig. 3A). Oceans are generally underlain by a less viscous asthenosphere and higher viscosity slabs appear beneath subduction zones at greater depth. The general patterns and order of magnitude viscosity variations are comparable to previously derived viscosity structures (Li et al., 2018). For our GIA calculations, we superimpose the lateral viscosity perturbations shown in Fig. 3 on different 1D viscosity profiles. Our default simulations use a 1D viscosity profile referred to as p55, which consists of an upper mantle viscosity of $5 \times 10^{20} \mathrm{~Pa} \mathrm{~s}$ and a lower mantle viscosity of $5 \times 10^{21} \mathrm{~Pa} \mathrm{~s}$ (Raymo et al., 2011). Uncertainties in inferred Earth structure and their impacts on GIA predictions are addressed in the Discussion.

\section{Results}

We performed GIA calculations using both radially symmetric and laterally varying viscosity structure, which we will refer to as 1D and 3D simulations, respectively. Results and predictions from these simulations will be referred to as $1 \mathrm{D}$ and $3 \mathrm{D}$ results and predictions. The $1 \mathrm{D}$ viscosity model is identical to the average of the 3D viscosity model at each depth (averaging is done in log space) except in the analysis described in section 4.3. We first describe and explain the general patterns that are common to both $1 \mathrm{D}$ and $3 \mathrm{D}$ simulations. We next detail differences between 1D and 3D results in the near and far field, before comparing results at specific sites 

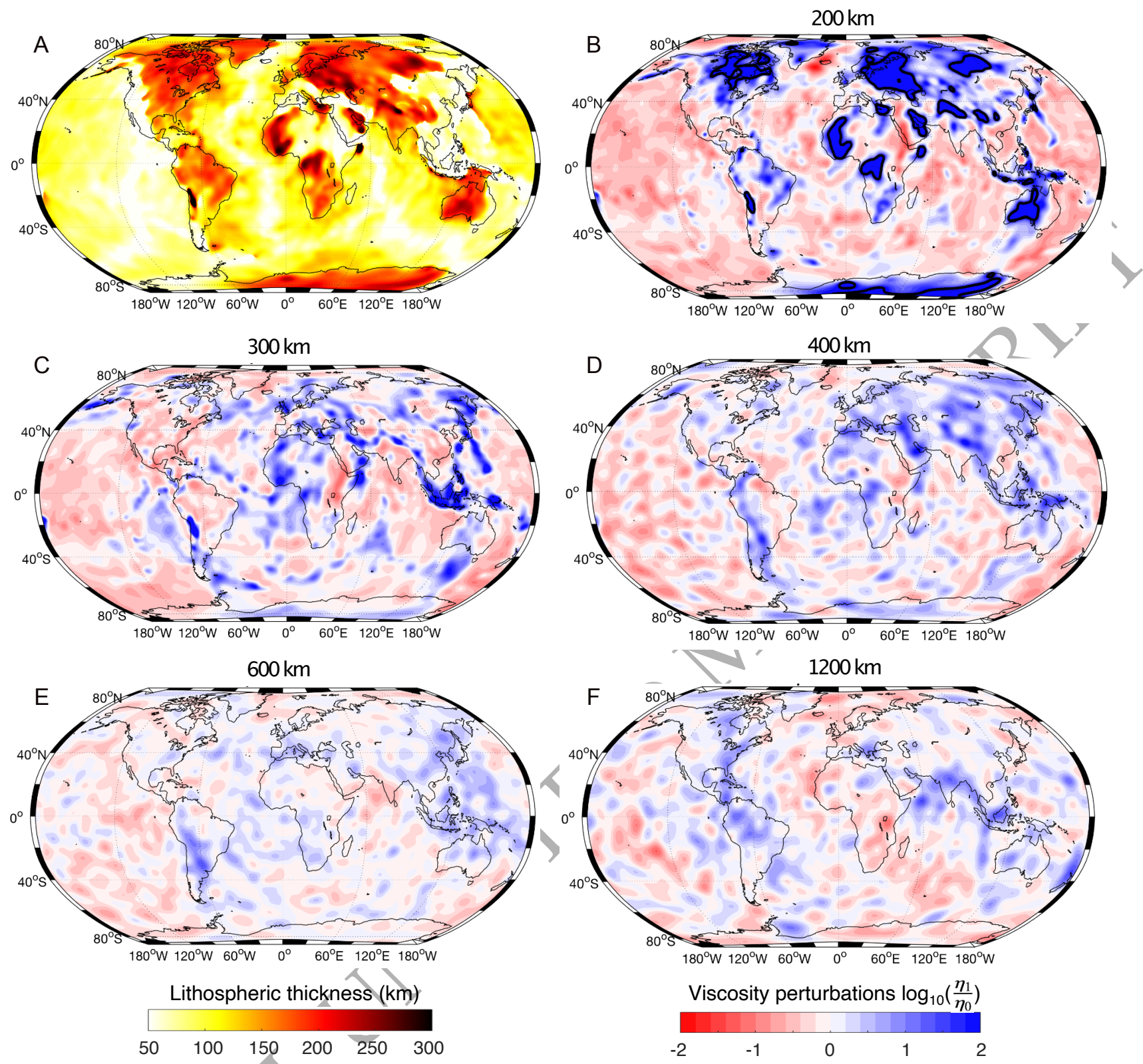

Figure 3: 3D viscosity structure of the Earth. A) Global lithospheric thickness variations, yielding a globally averaged lithospheric thickness of $100 \mathrm{~km}$ (colorbar at the bottom left). B-F) Lateral viscosity perturbations at depths of $200 \mathrm{~km}, 300 \mathrm{~km}, 400 \mathrm{~km}, 600 \mathrm{~km}$, and $1200 \mathrm{~km}$, respectively (colorbar at the bottom right). Thick black contour in panel (B) delineates lithospheric portions. 
with important sea-level indicators from the LIG.

\subsection{General patterns of GIA over the LIG}

Near field. GIA models predict that sea level changes over the course of an interglacial will vary significantly across the globe (Raymo \& Mitrovica, 2012; Dutton \& Lambeck, 2012; Dendy et al., 2017). At the beginning of the LIG (Fig. 4A), relative sea level (i.e., sea level relative to present day; Mitrovica \& Milne, 2003) is high in formerly glaciated regions because these areas are experiencing ongoing postglacial rebound in response to the just-completed deglaciation, while the peripheral bulges surrounding them are subsiding from an elevated position, leading to low values of relative sea level. That is, the solid Earth beneath the major ice sheets is in greater isostatic disequilibrium at the beginning of the LIG compared to today. For the Laurentide ice sheet, this pattern is reversed at the end of the LIG (Fig. 4B) at which time more rebound (and peripheral bulge subsidence) has occurred in comparison to today. This is the case because the LIG was longer than the present interglacial and because our ice history adopts a Laurentide ice sheet that was smaller during the PGM than the LGM. In contrast, the results for the Fennoscandian region suggest more isostatic disequilibrium at the end of the LIG compared to today (Fig. 4B) - the formerly glaciated area remains below present levels while the peripheral bulge sits above present levels. In this case, the greater size of the Fennoscandian ice sheet at PGM relative to the LGM more than compensates for the fact that the duration of the LIG was longer than the duration of the present interglacial.

Far field. First-order sea-level patterns in the far field include continental levering, ocean syphoning, and rotational effects (Mitrovica \& Milne, 2002). Continental levering - a tilting of the crust at continental shorelines - is driven by the loading and unloading of the oceans by the water produced from ice melting, while the adjacent continents experience nø such load changes. During interglacials, the process leads to a progressive rise in sea level on the oceanward side of a continental shoreline and a fall on the continent side of the shoreline. The length scale of this effect is related to the thickness of the lithosphere, with thicker lithosphere leading to a broader levering signal that extends further away from the shoreline. The levering process is significantly more advanced at present day relative to the start of the LIG, leading to the strong gradient in sea level on a transect across most shorelines (Fig. 4A). In contrast, at the end of the LIG, the levering process is somewhat more advanced than at present day, and the gradient along the transect is therefore of opposite sign and smaller in magnitude (Fig. 4B). In the middle of ocean basins, ocean-syphoning - the migration of water away from such

regions and largely toward subsiding peripheral bulges - dominates sea-level physics during interglacials and 



$\begin{array}{lllllllllllllllllll}-45 & -35 & -25 & -15 & -5 & -4 & -3 & -2 & -1 & 0 & 1 & 2 & 3 & 4 & 5 & 15 & 25 & 35 & 45\end{array}$

Figure 4: LIG sea level predictions assuming 1D and 3D Earth structure. A, B) Prediction of relative sea level at the beginning (128 ka) and end (117 ka) of the Last Interglacial, respectively, assuming radially symmetric Earth structure. C, D) Same as A, B but including lateral variations in lithospheric thickness and mantle viscosity. The a-a' transect indicated in panel A is used in Fig. 6.

drives a sea-level fall. At the beginning of the LIG, this process is less advanced than at present day and sea level is higher than at present (Fig. 4A), while at the end of the (longer duration) LIG, the opposite is true and sea level is lower (Fig. 4B).

Models that include lateral variability in Earth structure exhibit the same first-order patterns described above (Fig. 4C, D). However, there are notable shorter wavelength differences that arise due to lateral variations in both lithospheric structure (Fig. 5A, B), and mantle viscosity (Fig. 5C, D). The magnitude of the difference between 1D and 3D predictions is largest in the near field, where it is on the order of several to tens of meters. The difference is smaller, but still up to few meters, in the far field of ice sheets (Fig. 5E, F). In the next section, we analyse in more detail the differing GIA responses.

\subsection{Near-field effects of lateral variations in Earth structure}

Lithospheric thickness variations alone. Both regions that were covered by massive ice sheets during the

PGM, Fennoscandia and Canada, are largely cratonic regions with a thick continental lithosphere (Fig. 3A). 

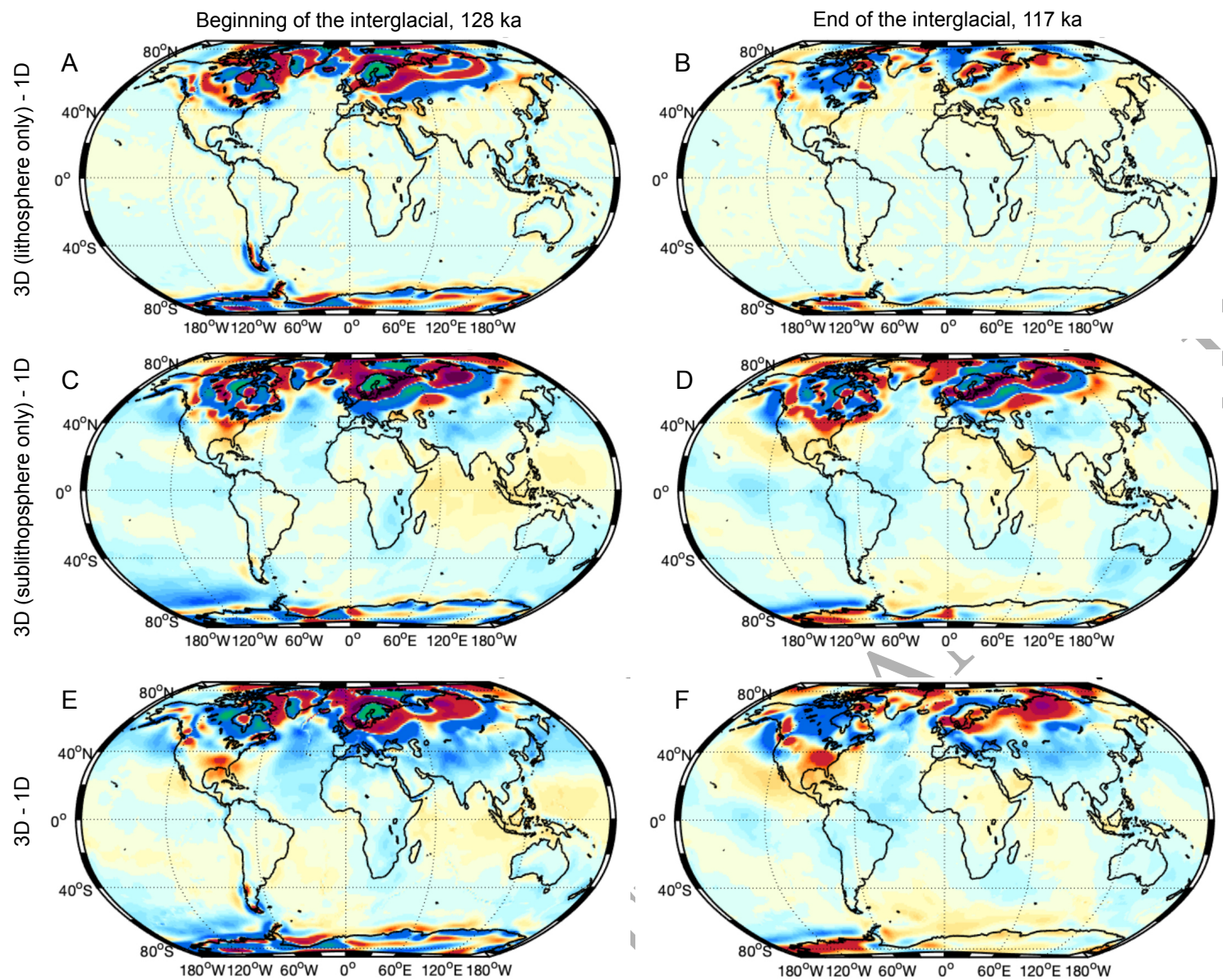

Figure 5: Effect of lateral variations in Earth structure on LIG sea level. A, B) Difference in predicted sea level at the beginning (128 ka) and end (117 ka) of the Last Interglacial, respectively, between a simulation with variable lithospheric thickness above a radial viscosity profile and one with constant lithospheric thickness. C, D) Difference in predicted sea level at the beginning (128 ka) and end (117 ka) of the Last Interglacial, respectively, between a simulation with variable sublithospheric viscosity variations and one with radially symmetric viscosity (both simulations have a constant lithospheric thickness). E, F) Difference in predicted sea level at the beginning (128 ka) and end (117 ka) of the Last Interglacial, respectively, between a simulation including lateral variations in both lithospheric thickness and viscosity, and a purely radial model. 
This similarity leads to similar patterns in North America and northern Europe when comparing the 1D and 3D results (Fig. 5A). The thicker lithosphere underneath the former Laurentide ice sheet leads to less subsidence and a more distal peripheral bulge during the glacial maxima. At the beginning of the LIG, when ice sheets were recently melted, this leads to higher topography (or lower sea level) in the centre of the former ice sheet with a broader peripheral bulge (Fig. 5A; Fig. 6A). Towards the end of the LIG, as the peripheral bulge continues to subside, the difference between the 1D and 3D results is small (Fig. 5B; Fig. 6B). Sea level in Fennoscandia exhibits a similar pattern at the beginning of the LIG except in western Europe (UK, Germany, France), which can be explained by the much thinner lithosphere in this region (Fig. 3A). The predicted response evolves towards the end of the LIG as the centre of rebound shifts slightly northwards (Fig. 5B).

Lateral variability in both lithospheric thickness and mantle viscosity. We next consider the effects of including lateral variations in mantle viscosity in addition to lithospheric thickness variations. In Fennoscandia, the patterns change only slightly, most notably in western Europe (UK, Germany, France). These areas have a thin lithosphere but are underlain by mantle at $300-400 \mathrm{~km}$ depth that is $1-2$ orders of magnitude more viscous than the global average. This high-viscosity feature, which is a slab associated with the closure of the Tethys Ocean (specifically the ApennineâĂŞCalabrianâĂŞMaghrebides slab; Fichtner et al., 2013; van Hinsbergen et al., 2014), causes a widening of the peripheral bulge observed in the 3D-1D difference, both at the beginning and end of the LIG (Fig. 5 C-F). Considering the peripheral bulge of the Laurentide ice sheet along the US East coast, we find that lateral viscosity variations bring the location of the bulge closer to the former ice sheet (Fig. $5 \mathrm{C}$, D) while remaining similar in amplitude (Fig - 6A). A significant difference between the 3D simulation and the 1D result is visible at the southern end of the peripheral bulge (i.e. south of $\sim 37^{\circ} \mathrm{N}$ ), which is underlain by low viscosity mantle at $\sim 300 \mathrm{~km}$ depth (Fig. 6E). This weak region has previously been associated with active upwelling flow above the Farallon slab (Rowley et al., 2013). We speculate that the low viscosity in this region focuses deformation associated with the peripheral bulge and possibly also continental levering, leading to a relative sea-level high and more northern peripheral bulge in comparison to runs that only account for lithospheric thickness yariations (Fig. 6). This leads to a relative sea-level high that persists throughout the deglaciation and LIG (Fig. 4C-F; Fig. 6A-D). This response is also visible along the US west coast, which is generally underlain by lower viscosity mantle. It is, however, more localised at the edge of the former ice sheet, with a sea-level peak occurring around $47^{\circ} \mathrm{N}$. 

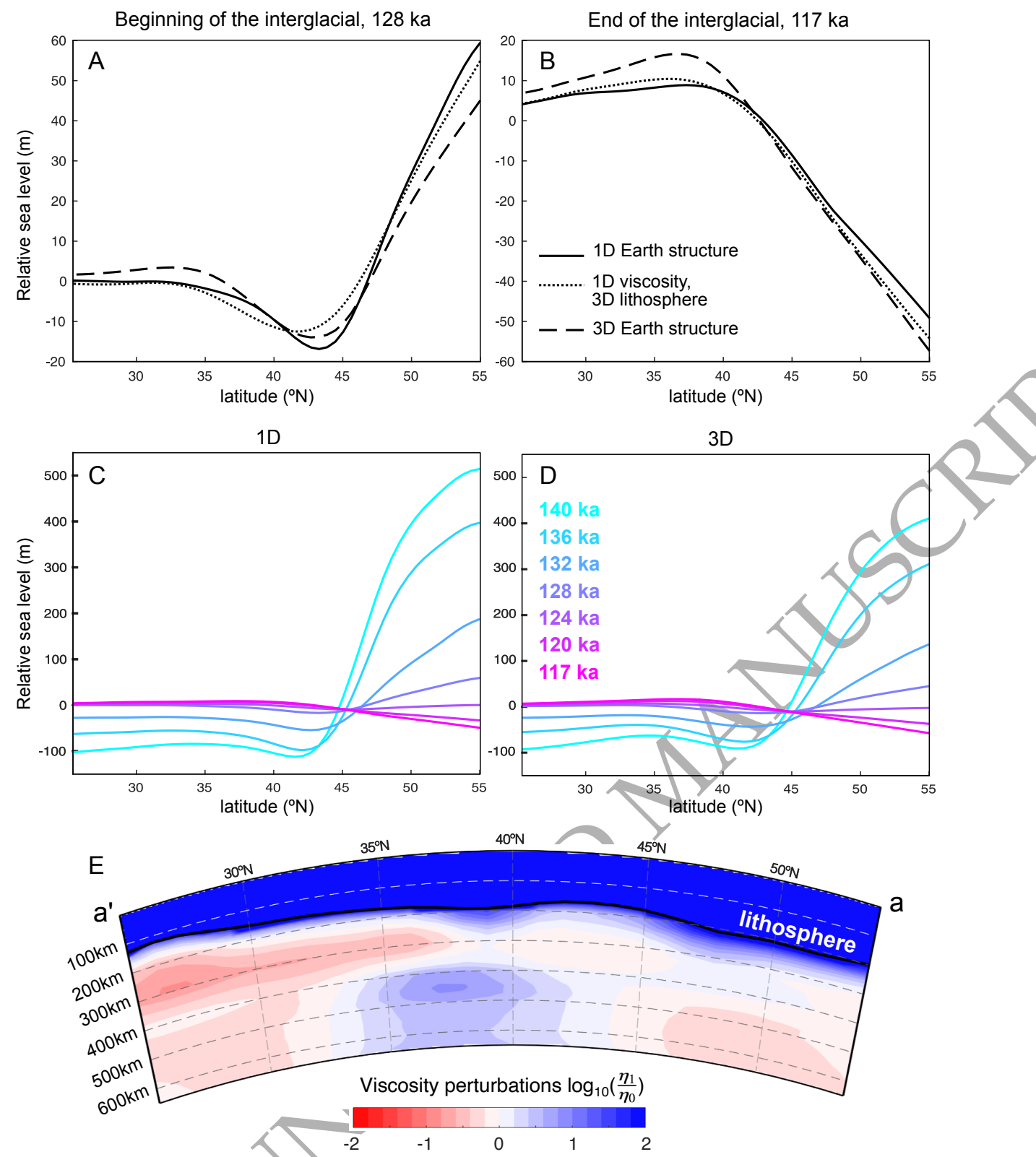

Figure 6: Near-field GIA effects due to lateral variations in Earth structure. A, B) Relative sea level at the beginning (128 ka) and end (117 ka) of the LIG across the peripheral bulge of the Laurentide ice sheet (a-a' transect of Fig. 4A). Results are shown for simulations using a 1D Earth structure (black line) with a constant lithospheric thickness of $100 \mathrm{~km}$, upper mantle viscosity $5 \times 10^{20} \mathrm{~Pa} \mathrm{~s}$, and lower mantle viscosity $5 \times 10^{21} \mathrm{~Pa} \mathrm{~s}$. The dotted and dashed black lines show the prediction using lateral variations in lithosphere alone and full 3D Earth structure (lithosphere plus mantle viscosity), respectively. C, D) Relative sea level using a 1D and 3D simulations along the same transect at different times during the deglaciation. E) Cross section of Earth structure along the transect from south to north. Viscosity perturbations are relative to the average upper mantle viscosity of $5 \times 10^{20} \mathrm{~Pa}$. 


\subsection{Far-field effects of lateral variations in Earth structure}

Lithospheric thickness variations alone. Many far-field sea-level sites are located at continental margins that sit on the transition from thinner oceanic lithosphere to thicker continental lithosphere (Fig. 3B). This differs for ocean island sites, which are generally situated on thinner oceanic lithosphere and can be underlain by lower viscosity if their origin is plume related. Lithospheric thickness variations affect far-field sea-level indicators more at the beginning of the LIG than the end (Fig. 5A,B) and in two specific ways: Firstly, thicker lithosphere leads to continental levering over a broader area rather than being focused in a narrow corridor along the coastlines. When the lithosphere is thicker on the landward side of the coastline, the continental levering signal becomes asymmetric. One location that exemplifies this situation is Western Australia (Fig. 7A, C). The amount of continental levering when including lateral variations in lithospheric thickness in the calculation is close to the $1 \mathrm{D}$ prediction on the oceanward side, where the lithosphere is only slightly thicker than $100 \mathrm{~km}$. However, predictions on the landward side are lower in amplitude and wider due to the thick $(\sim 200 \mathrm{~km})$ lithospheric root associated with the Yilgarn and Pilbara cratons (Fig. 7C). Secondly, large oceanic islands generally experience more continental levering when lateral variations in lithospheric structure are considered (Fig. 7D). This effect occurs because the lithosphere is typically thinner in oceanic settings than the $100 \mathrm{~km}$ global average. For example, the Seychelles are part of a granitic plateau in the western Indian Ocean that was exposed during the LGM and have a spatial extent of $50-100 \mathrm{~km}$ (Fig. 7B). The lithospheric thickness here is around $80-90 \mathrm{~km}$, and undergoes continental levering during exposure. Thinning the lithosphere further causes the levering to become more pronounced, while increasing it to $100 \mathrm{~km}$ or higher results in the loss of continental levering effects (Fig. 7D; Dendy et al., 2017).

Lateral variability in both lithospheric thickness and mantle viscosity. Understanding the far-field response to full 3D variability in Earth structure is challenging because far-field sea-level indicators are not only sensitive to local Earth structure, but also to structure beneath the melting ice sheets and their periphery and to deeper mantle structure along the path between these ice sheets and the far-field site (Crawford et al., 2018). In Western Australia, we observe that including lateral viscosity variations leads to a smoother continental levering signal (Fig. 7C). The 1D and 3D simulations exhibit long-wavelength, meter-amplitude differences throughout the ocean(basins, including a more positive sea level at the Seychelles (Fig. 7D). The slightly less pronounced continental levering in the full 3D simulation is due to the higher than average viscosity beneath the Seychelles plateau. Reducing the global average lithospheric thickness to $80 \mathrm{~km}$ instead of $100 \mathrm{~km}$ (while keeping lateral variations in viscosity the same) allows for more deformation related to continental levering and leads to an 

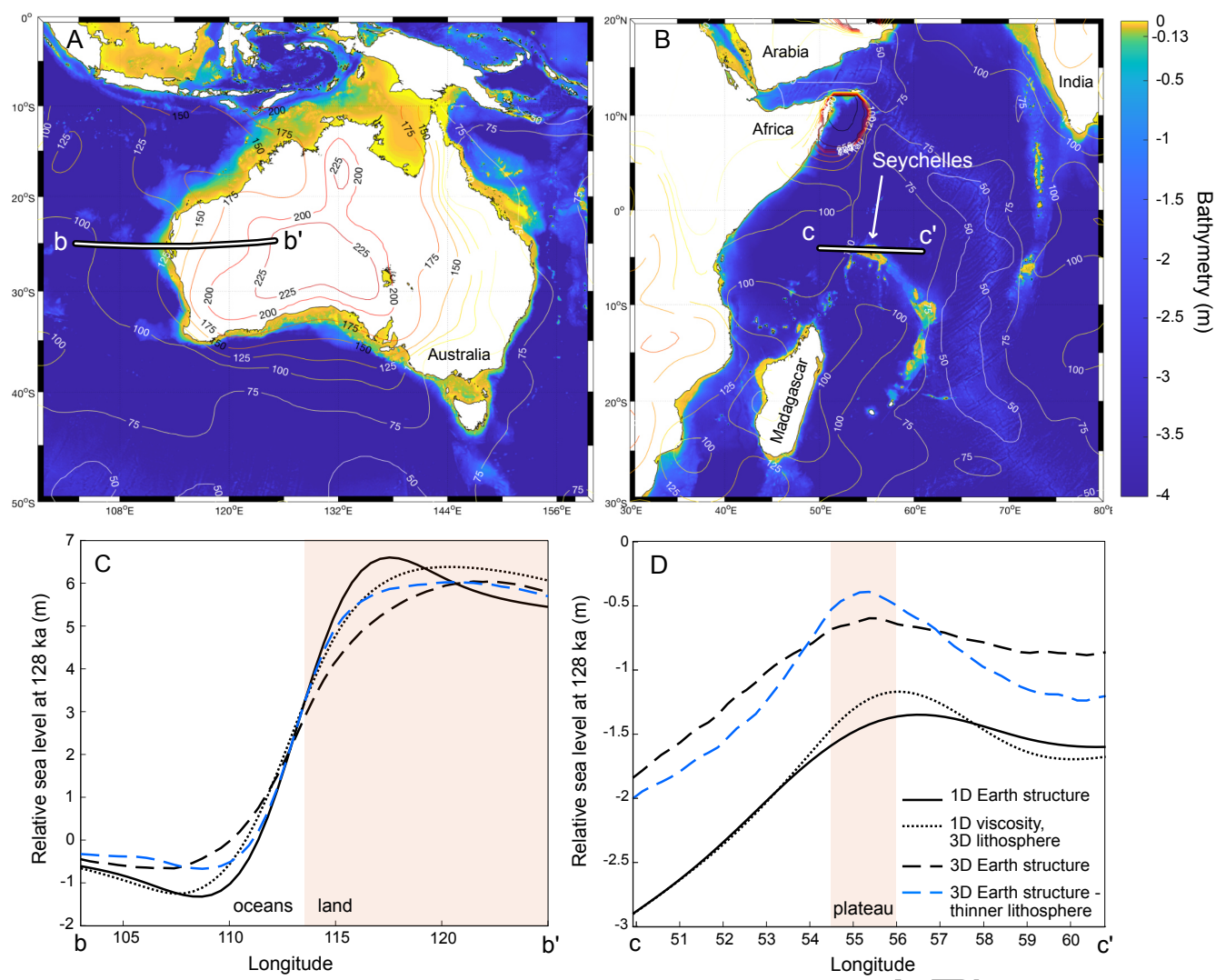

Figure 7: Far-field GIA effects due to lateral variations in Earth structure. A, B) Bathymetry around Australia and the Seychelles, respectively. Contour lines show lithospheric thickness in km. Relative sea level along the transects shown as black lines (b-b' and c-c') are displayed in panels C and D, respectively. C, D) Relative sea level is extracted at the beginning of the Last Interglacial (128 ka) and shown for simulations using a 1D Earth structure (black line) with a lithospheric thickness of $100 \mathrm{~km}$, upper mantle viscosity $5 \times 10^{20} \mathrm{~Pa} \mathrm{~s}$, and lower mantle viscosity $5 \times 10^{21} \mathrm{~Pa}$ s. The dotted and dashed black lines show predictions using lateral variations in lithosphere alone and full viscoelastic structure, respectively. The blue dashed line shows predictions using full 3D Earth structure (lithosphere plus mantle viscosity), but with a thinner lithosphere that has a global average of $80 \mathrm{~km}$ instead of $100 \mathrm{~km}$.

increased sea-level signal on the Seychelles plateau (Fig. 7D).

\subsection{Predictions of 3D GIA at key LIG sites}

Next we consider predictions at specific sites that have notable records of LIG sea level (Fig. 8).

Near-field locations. Bermuda and Mallorca are located on the peripheral bulge of the former Laurentide and Fennoscandian ice sheets, respectively. This forebulge subsides over the course of the LIG and therefore leads to sea-level rise if GMSL is assumed to be constant (solid black lines, Fig. 8E, F). Accounting for lateral variations in viscosity at Mallorca leads to a larger sea-level rise over the LIG (dashed black line, Fig. 8E). 
Bermuda, on the other hand, is located in a region that is not strongly affected by lateral variations in viscosity since the 1D and 3D predictions closely track one another (solid and dashed black line, Fig. 8E). We emphasise that the ice history (and relative size) of the Fennoscandian and Laurentide ice sheets, which are not explored here, will have a major affect on the GIA correction at these locations (Dendy et al., 2017; Rohling et al., 2017).

Ancient coral reefs in the Caribbean have long been used as paleo sea-level indicators. In particular, records from Xcaret on the Yucatan Peninsula (Blanchon et al., 2009) and various islands along the Bahamian archipelago (e.g., Hearty et al., 2007; Skrivanek et al., 2018; Dyer et al., in press.) have been influential due to the existence of fossil corals with low age uncertainty and good preservation. Being located on the tail end of the Laurentide peripheral bulge, these sites experience a small component of peripheral bulge subsidence (or equivalent sea-level rise) in addition to continental levering. In both regions, the rate of sea-level rise is higher in the 3D simulation, which might be related to a low viscosity in the asthenosphere (see section 3.2, Fígs. 6, 5), a trend that is particularly noticeable for the Yucatan Peninsula (Fig. 8C, D). Relative sea level predictions are slightly reduced in the 3D GIA simulation that assumes a thinner lithosphere (blue dashed lines in Fig. 8C, D). We also show predictions for Eleuthera in the northern Bahamas (yellow lines, Fig. 8D). For both 1D and 3D simulations, GIA predictions at Eleuthera are significantly different from the prediction at Great Inagua, which is expected given its location on the tail end of the peripheral bulge (Dyer et al., in press.). These differences demonstrate that applying a single GIA correction collectively to these sites is insufficient (Hearty et al., 2007; Clark et al., 2020) and that they should each be individually corrected prior to comparison (Dyer et al., in press.).

Far-field locations. The Seychelles and Western Australia are located in the far field of the former major ice sheets and have received substantial attention due to their high quality local sea-level reconstructions (Dutton et al., 2015b; O'Leary et al., 2013). Our 1D LIG sea-level prediction in the Seychelles is relatively constant and slightly below the global mean. Incorporating lateral variations in viscosity leads to a slight upwards shift by 0.5 $-1.0 \mathrm{~m}$, which is the result of a combination of a slightly thinner lithosphere and lateral viscosity perturbations (see section 3.3; Figs. 7; 8A). The Western Australian coast is located on a hinge point, with higher sea level predicted offshore and lower sea level predicted on land when comparing 3D and 1D simulations (section 3.3, Figs. 5, 7) Âs a result, predictions using lateral variations in Earth structure are quite close and only slightly lower than predictions using 1D Earth structure. At both far-field sites, relative sea level predictions are slightly increased at the beginning of the LIG and slightly decreased towards the end when assuming a 3D Earth model with a thinner lithosphere (blue dashed lines in Fig. 8A, B). 

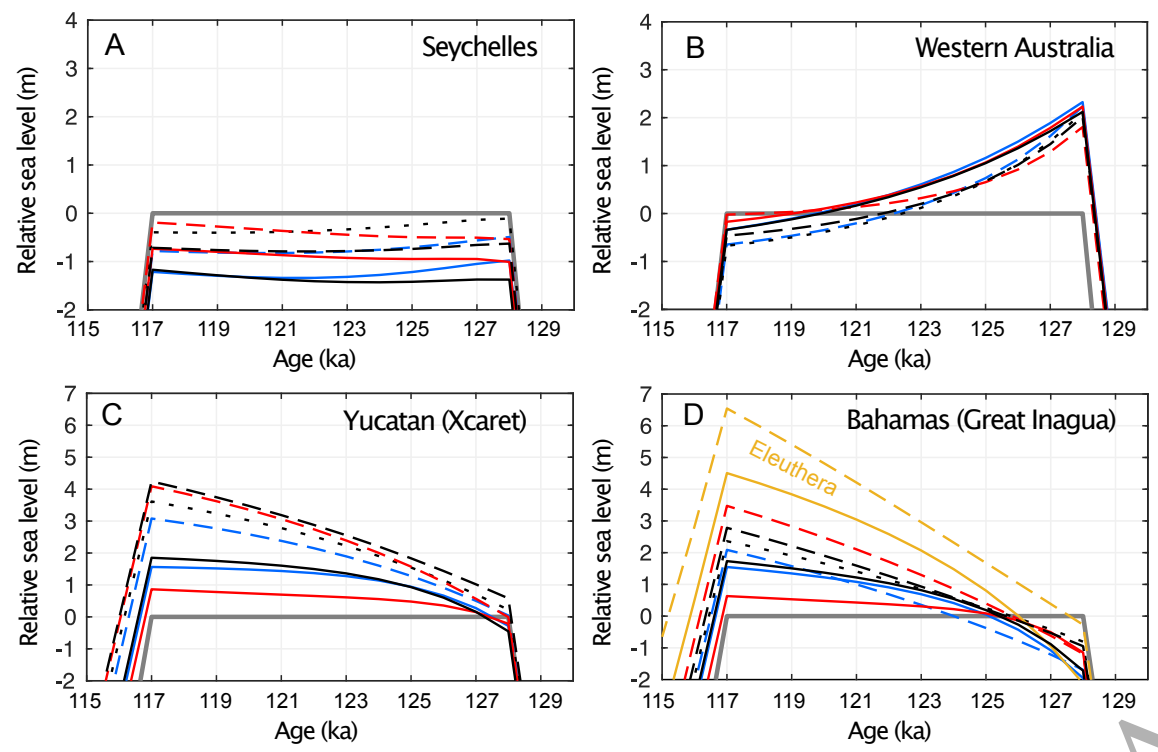

Modeled Eustatic

Log average viscosity: p55

upper mantle $0.5 \times 10^{21} \mathrm{~Pa} \mathrm{~s}$

lower mantle $5 \times 10^{21} \mathrm{~Pa} \mathrm{~s}$

Average lithospheric thickness: $100 \mathrm{~km}$

1D Earth structure

$==: 3 \mathrm{D}$ Earth structure 3D Earth structure

- . . higher activation energy

in the asthenosphere

Log average viscosity: p55

Average lithospheric thickness: $80 \mathrm{~km}$

1D Earth structure

- - . 3D Earth structure

Log average viscosity: VM5

upper mantle $0.5 \times 10^{21} \mathrm{~Pa} \mathrm{~s}$

lower mantle $1.6-3 \times 10^{21} \mathrm{~Pa} \mathrm{~s}$

Average lithospheric thickness: $100 \mathrm{~km}$
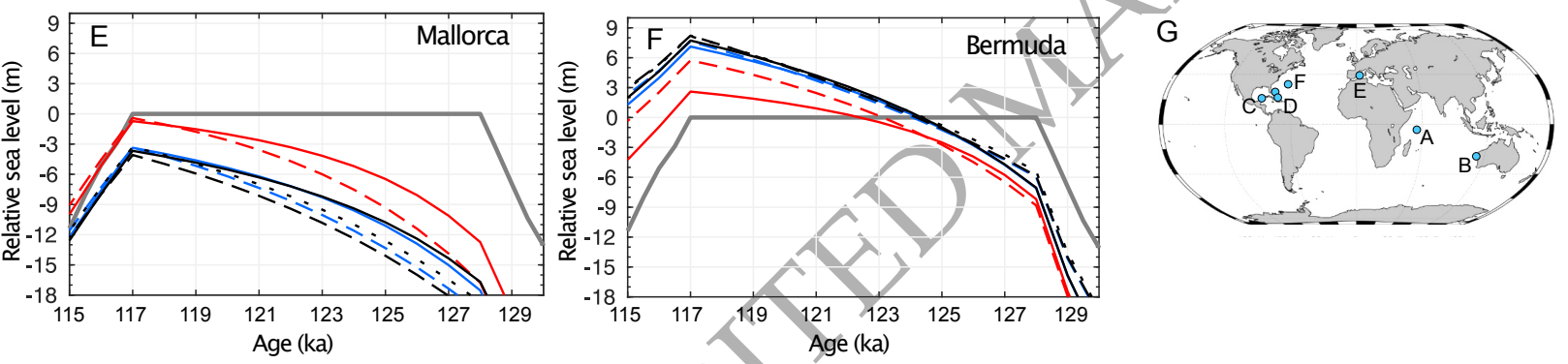

Figure 8: GIA time series at key sites. A-F) Local sea level at the Seychelles (La Digue), Western Australia (Cape Range), Yucatan Peninsula (Xcaret), Bahamas (Great Inagua and Eleuthera, Whale Point), Mallorca (Coves del Pirata), and Bermuda (Grape Bay), respectively. Thick gray line is the eustatic (global mean sea level) value assumed in the GIA model. Black lines show predictions of local sea level using a 1D (solid line) and 3D (dashed line, higher activation energy of $560 \mathrm{~kJ} \mathrm{~mol}^{-1}$ in the asthenosphere - dotted line) GIA model on top of the p55 average radial viscosity profile. The yellow line in panel D shows the 3D and 1D GIA predictions for Eleuthera (Bahamas) instead of Great Inagua (Bahamas). Blue lines are the same as black lines but use an average lithospheric thickness of $80 \mathrm{~km}$. Red lines are the same as black lines but use the background 1D viscosity VM5 (Peltier et al., 2015). G) Locations from A-F shown on a map. 


\section{Discussion}

The results presented above provide insight into the possible effects that lateral variations in lithospheric thickness and mantle viscosity can have on LIG sea level. Uncertainties remain in both the amplitude and pattern of viscosity perturbations, as we discuss in detail below. Ideally we would like to explore the full range of possible 3D Earth structures, however, this is currently not computationally feasible. On the other hand, 1D simulations are computationally inexpensive, and so we explore and discuss here two approximations: (1) we test whether the 3D effects (i.e. the difference between a 3D and 1D simulation, where the spherical average of the former is given by the latter) are consistent for different choices of 1D models; and (2) whether 3D GIA simulations can be approximated using 1D simulations where the 1D model differs from the spherical average of the 3D Earth model. We end our discussion by comparing our 3D GIA predictions to relative sea-level observations to understand how lateral variability in Earth structure may affect estimates of GMSL during the LIG.

\subsection{What are the uncertainties in Earth structure?}

There are three main factors that contribute to uncertainty in the mantle viscosity structure inferred from seismic tomography. The first involves the values of material properties that are used in the anelastic calibration (e.g. pressure- and temperature-dependence of the shear modulus and activation energy). The second is caused by inter-model differences in the seismic velocity structure imaged by different tomography studies. The third concerns the appropriate rheological deformation mechanism that is responsible for accommodating mantle flow during GIA. For the first two factors, our inverse anelastic calibration scheme provides a substantial advantage over traditional forward modelling approaches, which we illustrate in Fig. 9.

The traditional approach is to adopt material properties that have been measured in laboratory experiments and convert, in a forward sense, from seismic velocity to temperature and viscosity. Including the inherent uncertainties associated with these measurements introduces a spread in inferred Earth models. Our inverse calibration scheme, however, limits the number of acceptable combinations of material properties by retaining only those models that are consistent with the independent constraints on mantle structure (e.g. the thermal structure of oceanic lithosphere; Section 2.4.1). The approach reveals that there are trade-offs between the different material properties (Richards et al., 2020). Whilst uncertainty in any individual parameter remains large, exploiting their co-variance results in a substantial reduction in the range of inferred Earth models. 

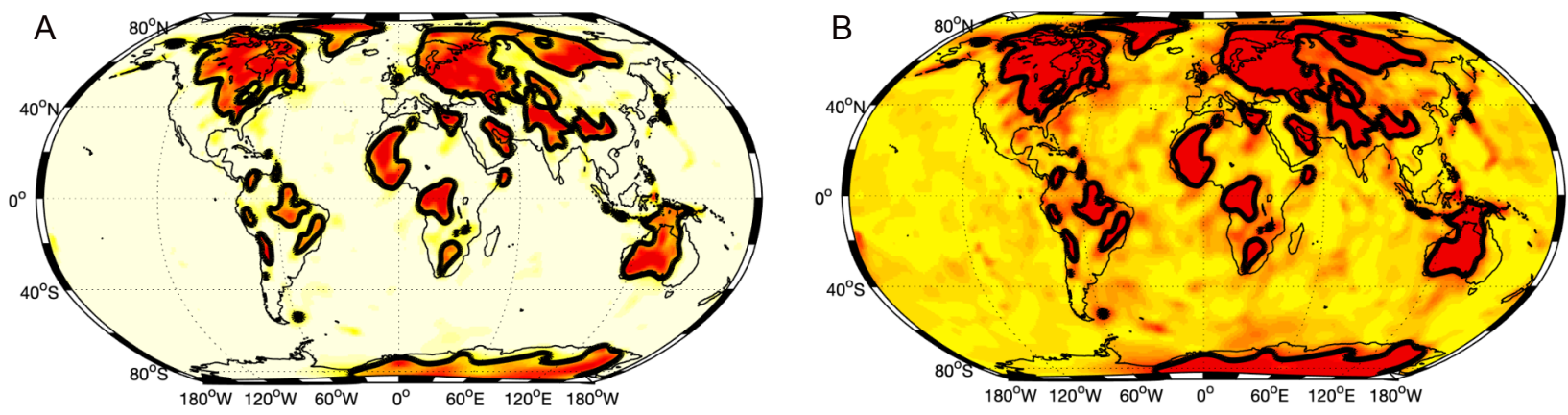

Standard deviation in viscosity perturbations
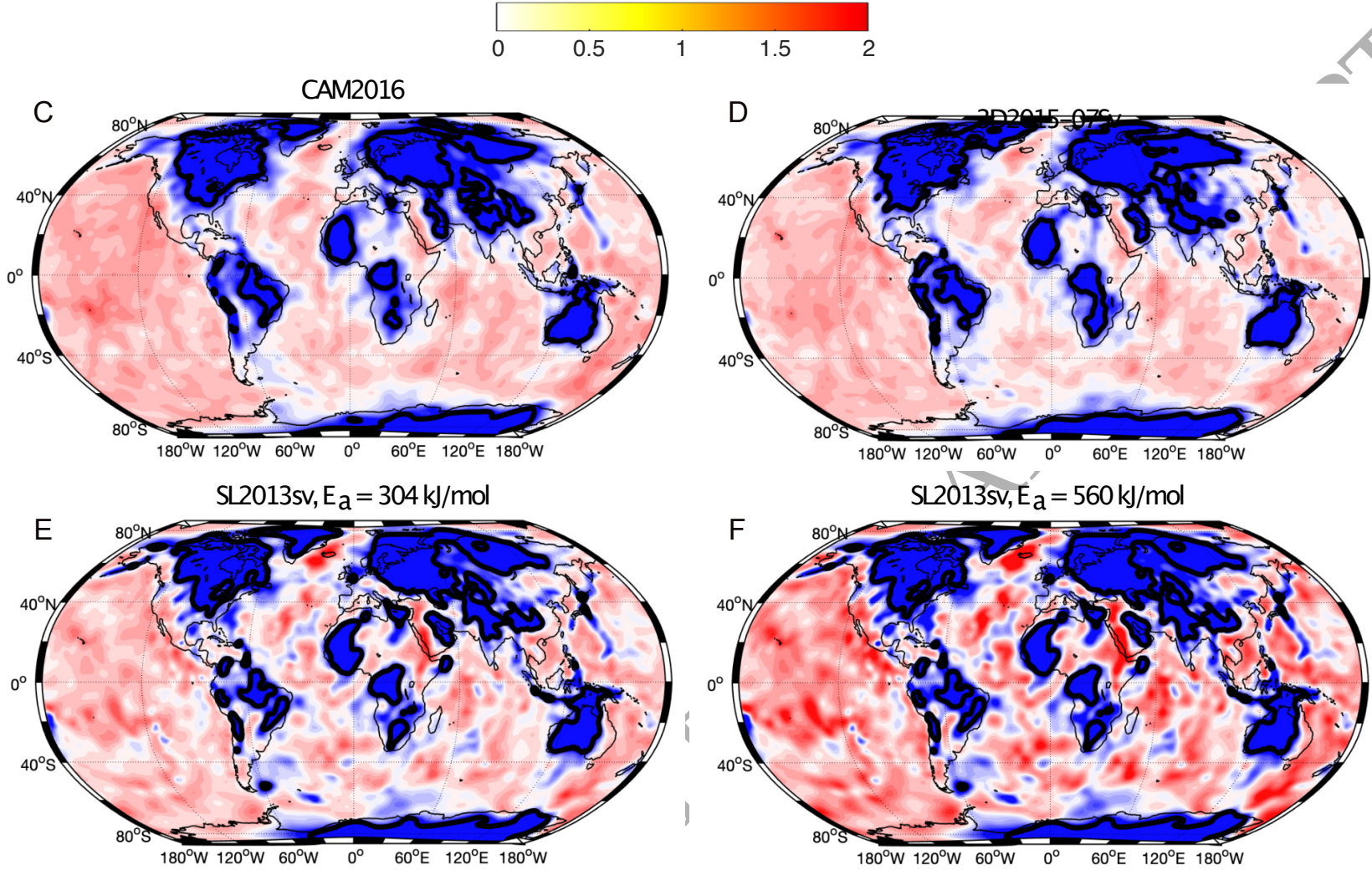

Viscosity perturbations $\log _{10}\left(\frac{\eta_{1}}{\eta_{0}}\right)$

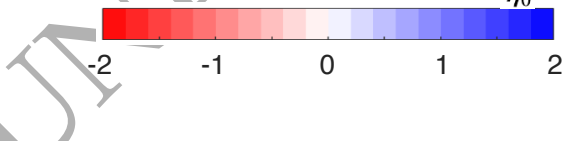

Figure 9: Uncertainties in inferred Earth structure. (A) Standard deviation in inferred diffusion creep viscosity at $175 \mathrm{~km}$ depth for one-thousand sets of anelastic parameters calibrated using the Richards et al. (2020) inversion scheme. Thick black line demarks lithosphere. (B) Same for a second suite of one thousand combinations of anelastic parameters, where each individual parameter is selected by randomly shuffling the values obtained in the construction of panel (A) and propagated into viscosity. Uncertainties are larger in this traditional forward mapping scheme due to the absence of information on the covariance between anelastic parameters. (C) Lateral viscosity perturbations at $175 \mathrm{~km}$ depth for an optimised calibration of CAM2016 seismic tomography model (Ho et al., 2016; Priestley et al., 2018). Thick black contour delineates the lithospheric portions. (D) As in (C), except for 3D2015-07Sv model (Debayle et al., 2016). (E) As in (C), except for our preferred SL2013sv model (Schaeffer \& Lebedev, 2013) and its optimal value of activation energy, $E_{a}=304 \mathrm{~kJ} \mathrm{~mol}^{-1}$. (F) Same as (E), except that lateral temperature variations obtained from the calibrated anelastic parameterisation have been converted into viscosity using $E_{a}=560 \mathrm{~kJ} \mathrm{~mol}^{-1}$, which is towards the upper end of the experimental range for dislocation creep in olivine. 
We illustrate this key benefit using a simple test. The initial step of the anelasticity optimisation procedure is a coarse parameter sweep that is designed to locate the approximate position of the global misfit minimum. These parameters are then used as starting values in the second stage, which employs Powell's algorithm to further minimise the misfit. For the test, we instead initiate this second stage from multiple different locations within the parameter space, discarding the result if the final misfit value returned by the algorithm is not smaller than the minimum value obtained in the coarse parameter sweep. In this manner, we obtain one thousand different sets of optimised anelasticity parameters that all yield satisfactory fits to the independent constraints. For each parameter, the range of optimal values across the one thousand sets is large and they remain individually uncertain. Nevertheless, the resulting standard deviation across all one thousand inferred viscosity structures is generally less than 0.2 orders of magnitude (Fig. 9A). Taking the set of one thousand values obtained for each individual anelastic parameter in the calibration stage, we can randomly shuffle them and construct a second suite of one thousand parameter combinations. This process yields the same total spread in individual material properties but removes information concerning their covariance (i.e., the information concerning which value of activation energy belongs with which value of reference viscosity, etc., is lost). Repeating the mapping from shear-wave velocity to viscosity (this time in a forward sense), we find that there is an approximately fivefold increase in the standard deviation of predicted viscosity models (Fig. 9B). Thus, our calibration scheme substantially reduces the uncertainty in inferred mantle viscosity structure. Exploiting parameter covariance in this manner is the strongest benefit of our inverse scheme over standard forward modelling practices.

The second source of uncertainty arises from differences in the starting seismic velocity structure between different tomography models. Choices including tomographic inversion technique, data content, reference velocity structure, and regularisation all introduce inter-model differences. Traditional forward mapping schemes convert this variability into uncertainty in Earth structure. Our inverse calibration, however, reduces this uncertainty because it requires each tomography model to individually yield a temperature structure that is compatible with the independent constraints, thereby forcing some of the inter-model seismic velocity variation into the resulting optimal anelastic parameters. In Fig.9C-E, we show results for three different surface wave tomography models, where the third case is the one used in this study: CAM2016 (Ho et al., 2016); 3D2015-07Sv (Debayle et al., 2016); and SL2013sv (Schaeffer \& Lebedev, 2013). The resulting pattern of lateral viscosity perturbations is relatively consistent between the three models, although the features in SL2013sv tend to be slightly more localised and of higher amplitude in comparison to the other two. For each model, the rootmean-squared value of lateral viscosity perturbations outside of the lithosphere is $0.84,0.75$, and $0.78 \mathrm{~Pa} \mathrm{~s}$, 
respectively. These values are more consistent with one another than the equivalent values obtained from forward mapping each tomography model using the same set of material properties $(0.68,0.60$, and $0.78 \mathrm{~Pa} \mathrm{~s})$.

The third source of uncertainty, that concerning the rheological mechanism by which the mantle deforms during GIA, is perhaps the most difficult to explore. The parameterisation for anelasticity at seismic frequencies of Yamauchi \& Takei (2016) yields a map of variations in the steady-state diffusion creep viscosity of the mantle. This deformation mechanism is consistent with our assumption in the GIA simulations that the mantle deforms like a Newtonian fluid. Nevertheless, it has also been suggested that deformation and flow during GIA may occur via dislocation creep, particularly in locations where strain rates are highest in the comparatively high-homologous-temperature asthenosphere (Huang et al., 2019; van der Wal et al., 2013). The dependence of dislocation creep viscosity on temperature (i.e. activation energy) has generally been found to be higher in laboratory experiments on olivine $\left(430-570 \mathrm{~kJ} \mathrm{~mol}^{-1}\right.$ versus $240-425 \mathrm{~kJ} \mathrm{~mol}^{-1}$; Karato \& Wu, 1993; Hirth \& Kohlstedt, 2003; Fei et al., 2012). Adopting mantle temperature variations obtained from the anelasticity parameterisation, we see that applying this higher activation energy in the asthenosphere (between the lithosphere and $300 \mathrm{~km}$ depth) would lead to larger lateral variations in viscosity (Fig. 9F). We use this scenario to explore the impacts of larger lateral viscosity variations on our sea-level reconstructions as might arise from dislocation creep, while still assuming diffusion creep in our calculations.

Fully propagating uncertainties in viscosity into our GIA predictions is outside the scope of this work. Nevertheless, in this and the following sections, we explore a few additional simulations. Using a viscosity model with a larger activation energy in the asthenosphere leads to sub-meter changes in predicted sea level in the far field (Fig. 10; dotted lines in Fig. 8). In the near field, where sensitivity extends deeper into the mantle (where both models have the same viscosity variations), the difference in the two predictions is on the meter scale, which is smaller than the sea-level change associated with introducing lateral variations in viscosity in the first place (Fig. 5E, F).

\subsection{Are 3D GIA effects dependent on the average viscosity profile?}

Our default simulations (p55) use a lower mantle viscosity of $5 \times 10^{21} \mathrm{~Pa} \mathrm{~s}$, however Peltier et al. (2015) have argued for a weaker viscosity at this depth. To explore the dependence of 3D GIA effects on the global average viscosity, we repeat our simulations with the VM5 viscosity profile in which lower mantle viscosity varies from 1.6 to $3.0 \times 10^{21} \mathrm{~Pa}$ s (Peltier et al., 2015). GIA predictions using these two different 1D viscosity profiles can differ significantly, especially in the near field (compare Fig. 11A,B to Fig. 4A,B). For example, the greater 


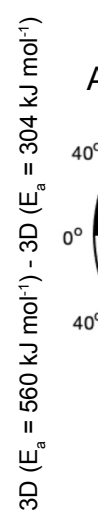

Beginning of the interglacial, $128 \mathrm{ka}$

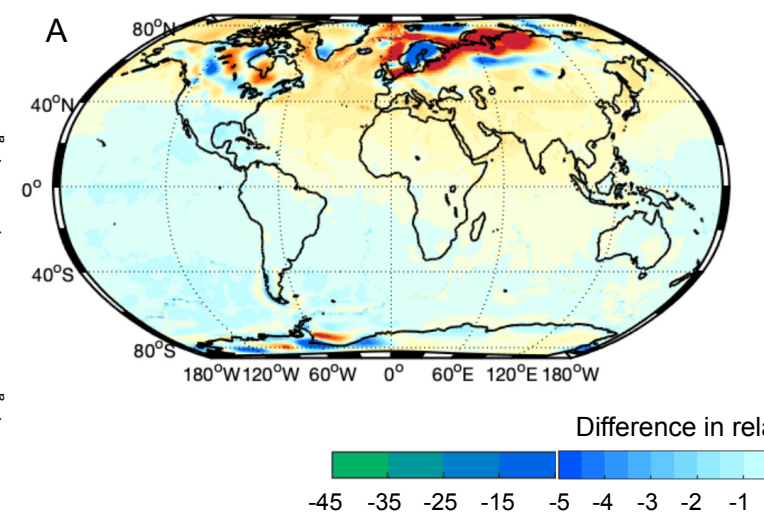

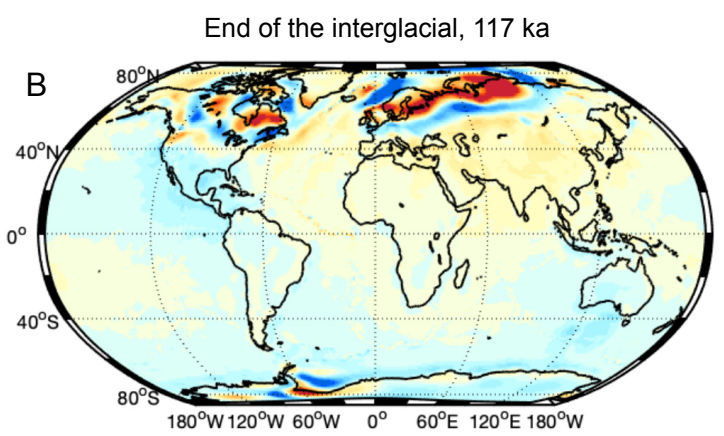

$\begin{array}{lllllllllllllllllll}-45 & -35 & -25 & -15 & -5 & -4 & -3 & -2 & -1 & 0 & 1 & 2 & 3 & 4 & 5 & 15 & 25 & 35 & 45\end{array}$

Figure 10: Effect of larger activation energy in the asthenosphere. A larger activation energy $E_{a}$ leads to higher amplitude viscosity variations, which is in line with expectations for dislocation creep, although we don't explicitly model this rheology. A, B) Difference in relative sea level between a 3D viscosity model that uses a higher asthenospheric activation energy (above $300 \mathrm{~km}$ depth) and the reference case at the beginning (128 ka) and end (117 ka) of the Last Interglacial, respectively.

lower mantle viscosity in our default 1D predictions (p55) results in lower sea level at Mallorca and higher sea level at Bermuda, Bahamas and Yucatan, compared to simulations using the VM5 viscosity profile (red lines in Fig. 8). Differences are smaller in the far field at sites such as the Seychelles and Western Australia $(\sim$ tens of centimetres).

Using these results, we investigate whether the incorporation of lateral variations in viscosity has the same effect whether the p55 or VM5 depth average viscosity is adopted in the simulation. Note that the lateral variations in viscosity shown in Fig. 3 are superimposed on these two 1D profiles such that the spherical average of the logarithm of viscosity at each depth remains unaffected. Comparing the results in Fig. 5E, F to Fig. 11E, F indicates that the impact of lateral viscosity structure is qualitatively similar; however, differences in magnitude and geometry exist (Fig. $11 \mathrm{G}, \mathrm{H}$ ) . This similarity is also evident when comparing results at specific locations: At Mallorca, for example, we find that while the choice of the 1D profile results in two different sea-level predictions (black versus red solid line in Fig. 8E), the signal due to the introduction of lateral variations is consistent (black and red dashed lines). On the peripheral bulge of the former Laurentide ice sheet, this signal has the same sign but differs in magnitude from site to site and is generally larger when adopting the VM5 viscosity profile. For example, at Bermuda, the sea-level predictions based on the p55 1D and 3D simulations are similar (within $\sim 0.5 \mathrm{~m}$; black solid versus dashed line in Fig. $8 \mathrm{~F}$ ), while the effect of adding lateral variations in viscosity is much larger when assuming the VM5 viscosity profile $(+3 \mathrm{~m}$ towards the end of 
the LIG; red solid versus dashed line in Fig. 8F). For the three sites in the vicinity of the Laurentide peripheral bulge (Xcaret, Bahamas, and Bermuda), the two 3D predictions are more consistent with one another than their associated 1D predictions, particularly for Xcaret where these differences remain less than $1 \mathrm{~m}$ throughout the LIG (Fig. 8C, D, and F). In the far field, we find that the introduction of lateral variations in viscosity tends to consistently increase local relative sea-level predictions at the Seychelles by up to $\sim 1 \mathrm{~m}$ and decrease them by a similar amount in Western Australia.

\subsection{Can 3D simulations be approximated with 1D simulations that are not the spherical average of the 3D Earth model?}

Given the computational expense of 3D GIA simulations, it is worth investigating whether a simulation with a suitable 1D viscosity profile, which is not necessarily the spherical average of the 3D Earth model, can be used to approximate the 3D result with sufficient accuracy. Powell et al. (2019) considered synthetic GPS observations in Antarctica and found that 1D simulations tuned to Earth structure local to the sites do not provide consistently accurate approximations to the 3D synthetic predictions. Hartmann et al. (2020) have proposed an approach which combines the result from different 1D simulations to approximate the 3D result. They focus on Antarctica and argue that the approach has promise, but concede that it might be inaccurate in areas where the ice load and sea-level observation are relatively distant from one another. The latter situation is the case for most sea-level studies that consider observations distant from the former ice margins, such as this study. Crawford et al. (2018) used an adjoint approach to produce 3D sensitivity kernels that isolate regions of the mantle that are sampled by a given sea-level record and predict whether increasing or decreasing viscosity in these regions will lead to a better fit between the model prediction and the sea-level observation. They found that the sensitivity is centred below the location of the sea-level record and extends towards the locations of ice melt. Moreover, their time-dependent sensitivity kernels indicate that the region of greatest sensitivity will vary over time. These results suggest that approxímating 3D Earth structure using 1D simulations may be challenging. Nevertheless, we explore two approaches here: First, we take a depth-average of the 3D Earth model in the vicinity of each individual sea-level site (averaging is performed in logarithmic space and within a maximum distance of $3^{\circ}$ around the sea level site; Fig. 12A-F) and repeat our 1D simulations using this local structure. Second, we use a broad suite of different viscosity profiles to assess whether any of them can provide a good approximation to the 3D GIA result.

The locally averaged Earth structure obtained from the 3D model below the six key sea-level locations shows 

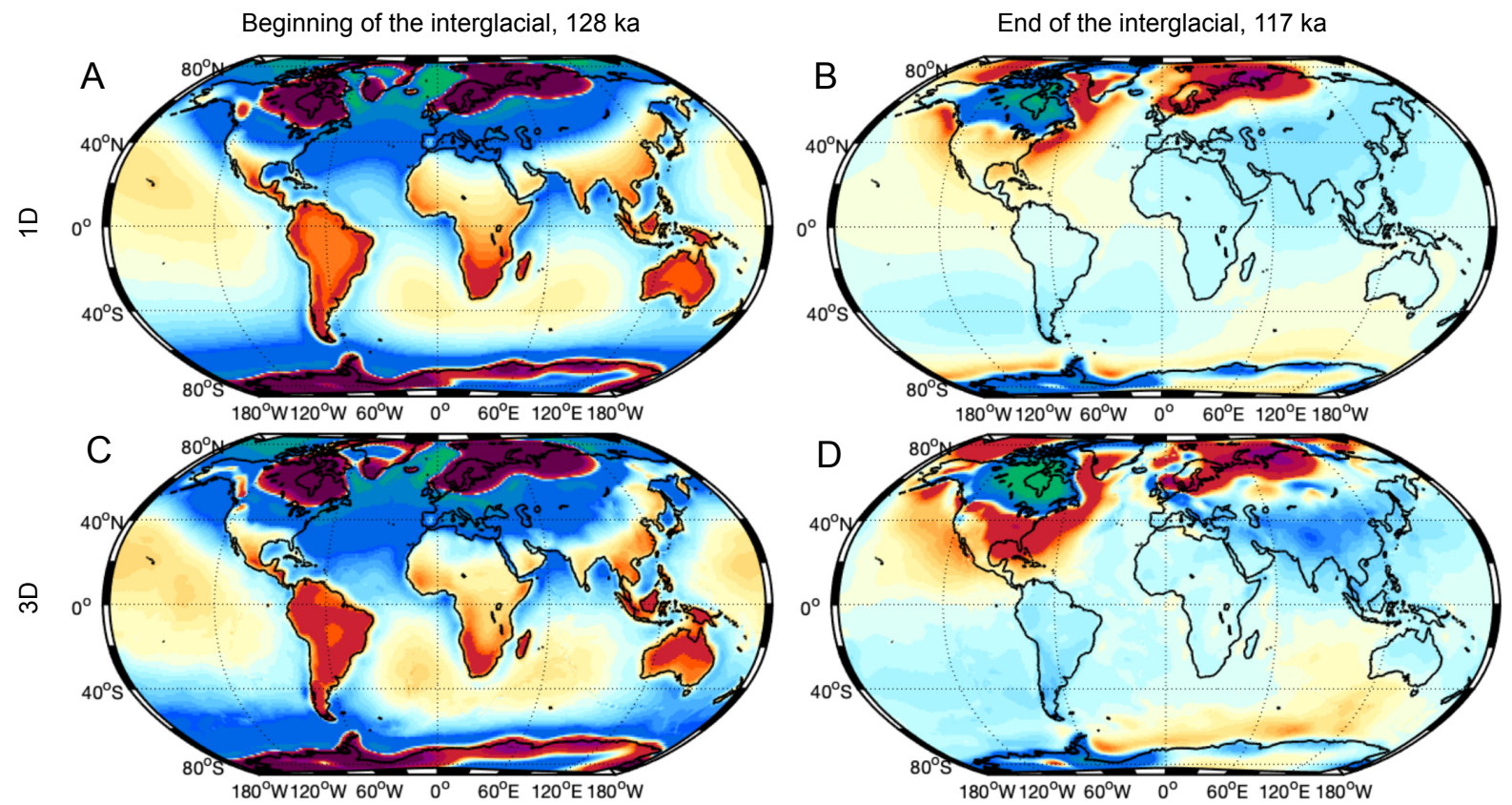

End of the interglacial, $117 \mathrm{ka}$

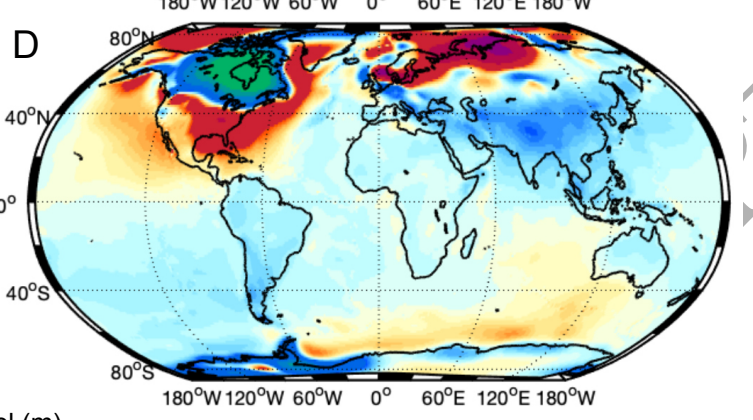

Sea level $(m)$
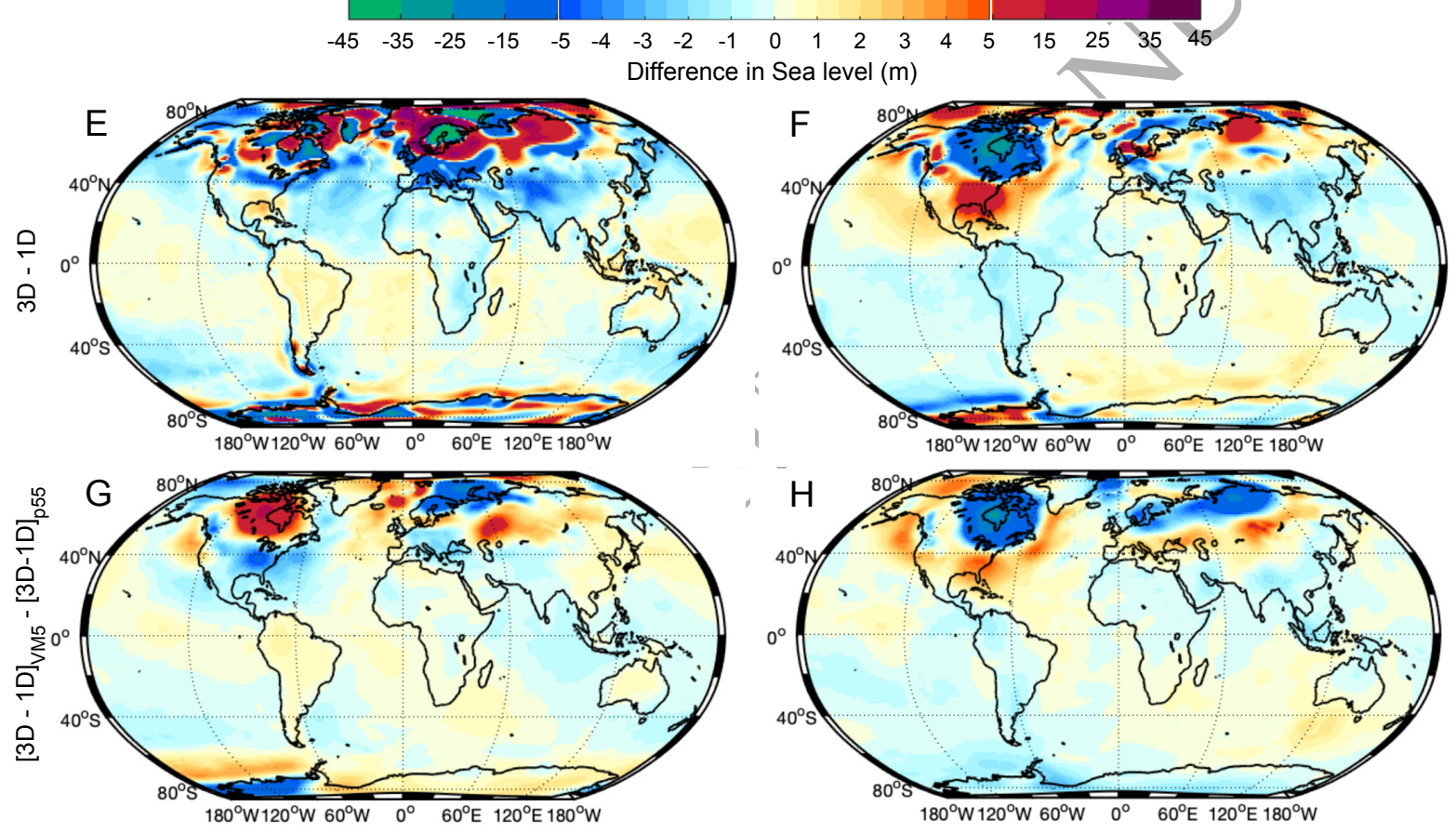

Figure 11: Effect of the choice of the 1D background viscosity on LIG sea level. A, B) Relative sea level at the beginning (128 ka) and end (117 ka) of the Last Interglacial, assuming the radially symmetric Earth structure VM5 (Peltier et al., 2015). C, D) Same as A, B but including lateral variations in lithospheric thickness and mantle viscosity. E, F) Differences in relative sea level between model simulations that do and do not account for lateral variability in Earth structure. G, H) A comparison of the effect of lateral variations in viscosity when superimposed on the VM5 and p55 viscosity profiles. Plots show the difference in the 3D effect, i.e. the difference between panels $\mathrm{E}$ and $\mathrm{F}$ of this figure and panels $\mathrm{E}$ and $\mathrm{F}$ of Fig. 5 
that most of them have a weaker than average upper mantle viscosity (Fig. 12A-F), which is not surprising given that most of them are distant to subduction zones and cratonic regions. The only exception is Mallorca, which has a higher than average viscosity in the deeper half of the upper mantle due the presence of a subducted slab. Local viscosity variations in the lower mantle are more variable, with larger differences in particular in the vicinity of the core-mantle boundary, which will have limited influence on the GIA response. Figures $12 \mathrm{G}-\mathrm{L}$ compare the result from the 1D simulations adopting local Earth structure (purple line) with the full 3D result (black dashed line). The two results are consistent for the Yucatan peninsula and Western Australia (Fig. 12G, I), but do not agree well elsewhere.

We next test a range of 1D Earth models to investigate which (if any) structure approximates the local 3D result for each site. We consider 48 different three-layer radial Earth models that each consist of an elastic lithosphere overlying isoviscous upper and lower mantle regions. We systematically vary upper and lower mantle viscosity across $3-5 \times 10^{20} \mathrm{~Pa}$ s and $3-40 \times 10^{21} \mathrm{~Pa}$ s, respectively, and test two different lithospheric thicknesses (71 km and $96 \mathrm{~km}$; see Fig. 12A). The $1 \sigma$ range of all model simulations is shown in green in Fig. 12G-L. Sites in the far-field are most sensitive to lithospheric thickness variations and upper mantle viscosity since continental levering is an important driver of sea level change for these sites. Sites on the peripheral bulge of the former ice sheet are more sensitive to mantle viscosity: Mallorca is most sensitive to lower mantle viscosity, and Bermuda, Great Inagua, and Xcaret are equally sensitive to upper and lower mantle viscosity.

We next compare our predictions for each 1D simulation to the 3D result at the six sites, calculating misfit using the root-mean-square difference in relative sealevel over the LIG (between $117 \mathrm{ka}$ and $128 \mathrm{ka}$ ). The misfit, which is shown as a function of upper and lower mantle viscosity in Fig. 12M-R, shows a strong dependence on Earth structure for near-field sites (Fig. 12O-R) and a weaker dependency for far-field sites (Fig. 12M,N). We find that the best fitting 1D Earth model at each site does produce a sea-level prediction that matches the 3D simulation reasonably well (green line compared to black dashed line in Fig. 12G-L). It is difficult to compare the local Earth structure to the best-fitting 1D Earth structure given the coarse resolution of the latter, however, the two show some consistency at far-field sites (green line compared to purple line in Fig. 12C-F). Differences between the local and best fitting 1D Earth structure are expected given the broad sensitivity of sea-level observations, which integrates Earth structure across wide regions of the mantle (Crawford et al., 2018). While the difference in the relative sea level prediction using a local structure versus the full 3D Earth structure argues against using the former as an approximation for the 3D result, the suite of 1D results suggest that a suitable 1D approximation may exist at each site. Inferring radial Earth structure from observations at 
these sites would generally lead to overestimates of the average lower mantle viscosity. In other words, while the global average viscosity in the lower mantle in these simulations is $5 \times 10^{21} \mathrm{~Pa}$ s, the viscosity of the best fitting 1D model at all sites except for the Seychelles is higher than that value.

Finally, the above analysis raises the question: how useful is it to use a range of 1D viscosity models when estimating uncertainties in the GIA correction (particularly uncertainties introduced by Earth structure)? The green band in Fig. 12G-L shows the $1 \sigma$ uncertainty range associated with the full ensemble of 1D Earth models used here (the mean is not shown, but it sits in the middle of the light green band). In the near field, the 3D result falls within the $1 \sigma$ range of 1D predictions (Fig. 12I-L). In the far field, the uncertainty range is relatively narrow and the 3D prediction falls just outside of this $1 \sigma$ range, but within the $2 \sigma$ range (Fig. $12 \mathrm{G}, \mathrm{H}$, note that the $2 \sigma$ is not shown). We thus consider that results based on a range of $1 \mathrm{D}$ model runs may proyide a suitable estimate of the uncertainty associated with the potential signal from lateral variations in viscosity structure.

\subsection{How do lateral variations in Earth structure affect estimates of Last Interglacial global mean sea level?}

Estimates of GMSL during the LIG are based on sea-level observations (such as corals or speleothems) from this time period. The locations we have chosen for our investigation (Fig. 8, 13) are among the sites with the most reliable local sea-level records. The inferred GMSL estimate at each site is given by the difference between observed sea level and that predicted by the GIA simulation. Sea level during the LIG will also vary spatially depending on which ice sheet is driving the excess melting (Hay et al., 2014), an issue which is not explored here.

In Mallorca, phreatic overgrowths on speleothems (POS) have been used to reconstruct local sea level, which the authors infer to be relatively stable throughout the LIG (Polyak et al., 2018; Fig. 13E). Given that relative sea level is predicted to steadily rise due to GIA, Polyak et al. (2018) concluded that GMSL must be falling over the LIG in order to result in constant relative sea level. Our result indicates that an even greater fall of sea level would be required if lateral variations in viscosity are accounted for (Fig. 13E). Bermuda is the other near-field site in our analysis, and stratigraphic and coral evidence suggests that local sea level peaked around $6-8 \mathrm{~m}$ above present; however the exact timing and evolution is controversial due to insufficient age control (Hearty, 2002; Muhs et al., 2020). Accounting for lateral variations in viscosity will tend to reduce the magnitude of the inferred GMSL and, assuming that the highstand was recorded late in the LIG, implies only a few meters of excess GMSL during that time. 

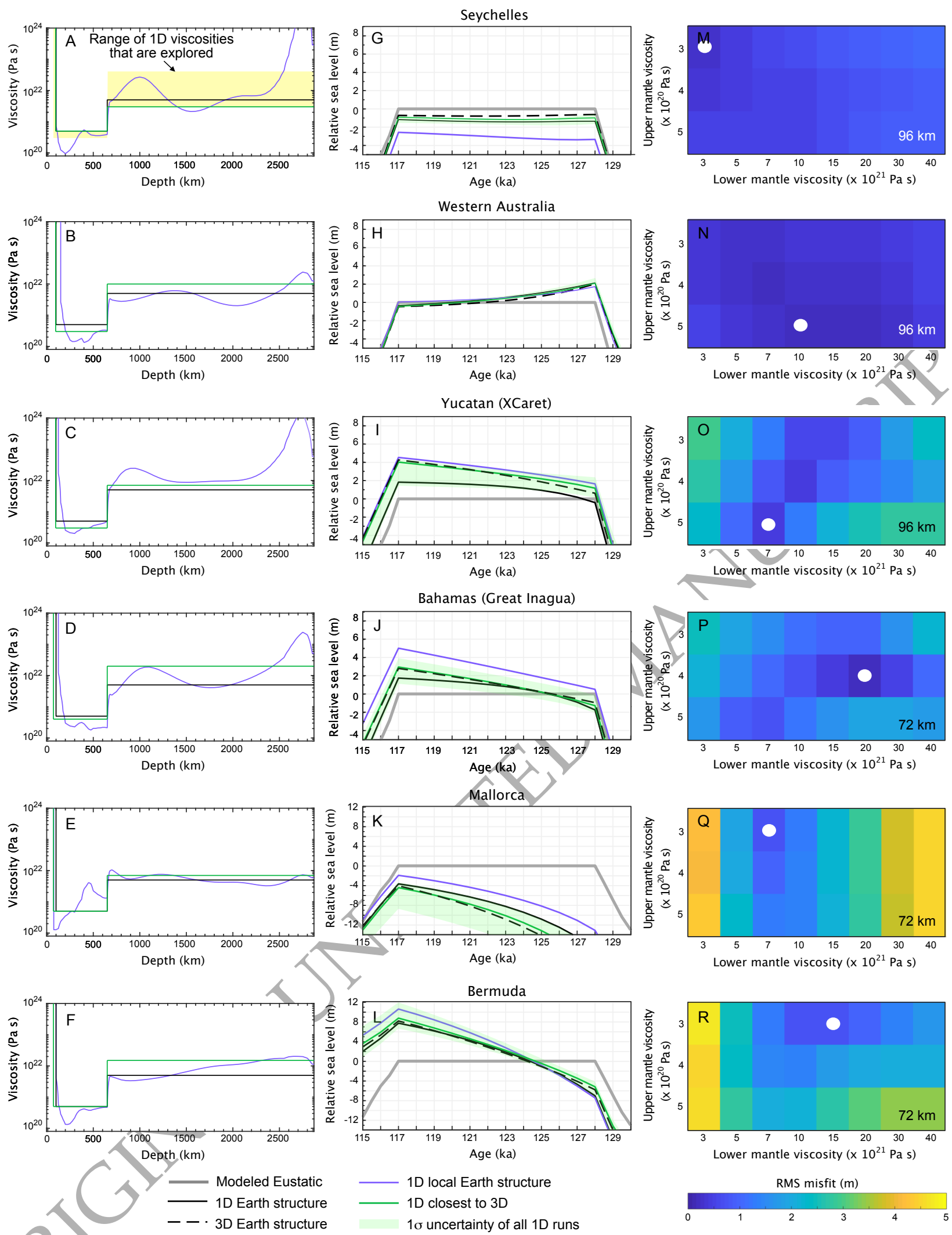

Figure 12: (Caption next page.) 
Figure 12: (Figure previous page.) Approximating 3D Earth structure with radially symmetric structure. A-F) Locally averaged viscosity structure as a function of depth from the 3D Earth model (purple), global average viscosity (black), and 3-layer 1D viscosity profile that best fits the 3D GIA prediction at each location (green). Yellow band in panel A shows the full range of 1D models explored here. To compute the locally averaged viscosity structure, the viscosity below the site was averaged across a maximum distance of $3^{\circ}$ from the sea level site at each depth. G-L) Local relative sea-level predictions at selected sites (see caption of Fig. 8 for exact locations) using the $1 \mathrm{D}$ viscosity profiles shown in panels $\mathrm{A}-\mathrm{F}$ with the same colours and also including predictions for the full 3D Earth structure (black dashed line). Thick gray line is the global mean sea-level value assumed in the GIA model. Light green range marks the $1 \sigma$ uncertainty range for the ensemble of 1D runs explored here. M-R) Parameter sweeps through upper and lower mantle viscosity (see text) at optimal lithospheric thickness for each site, showing misfit between each individual 1D prediction and the 3D prediction. The optimal lithospheric thickness is noted in the bottom right corner of each panel. The Earth model with the minimum misfit is shown by the white circle (this model is given by the green line in panels A-F).

More distal near-field records from the Yucatan Peninsula and the Bahamas show locally rising sea level, which are recorded by extensive coral reefs. At the ecological park of Xcaret, Blanchon etal. (2009) identified a lower and upper reef crest (Fig. 13C). In the Bahamas, Dyer et al. (in press.) used coral and sedimentary evidence combined with a large suite of radially symmetric GIA models to calculate a posterior relative sea-level history that exhibits an early sea-level rise, followed by slightly falling sea level before culminating in a final rise (Fig. 13D). This history is in agreement with earlier analyses from this location (Skrivanek et al., 2018; Dutton \& Lambeck, 2012). If one were to assume 1D Earth structure at these locations, one would infer $~ 3-$ $4 \mathrm{~m}$ of excess GMSL early and a smaller excess late in the interglacial, with a GMSL lowstand in the interim. The 3D GIA predictions are higher than the 1D predictions towards the end of the LIG, which may lower the inferred GMSL at the end of the LIG.

Far-field records along the western coast of Australia and in the Seychelles are also based on coral outcrops. O'Leary et al. (2013) dated corals at several locations in Western Australia and inferred an early rise in local sea level that was followed by a GIA-driven sea-level fall, which resulted in erosion of a coral platform (Fig. 13B). Additional higher corals were interpreted to reflect a late rise in sea level. Dutton \& Lambeck (2012) inferred a similar planated surface during the first half of the LIG and interpreted the higher corals to be tectonically deformed (see also Sandstrom et al., 2020). GIA and therefore inferred GMSL would be marginally impacted by 3D Earth structure at this location, which tends to increase inferred GMSL (by $\sim 0.5 \mathrm{~m}$ ). Inferred GMSL is $3-4 \mathrm{~m}$ at the beginning of the LIG (in line with earlier estimates) and remains at that level to the end of the LIG if the high corals are discounted or increases to $\sim 9 \mathrm{~m}$ if they are not. Lastly, extensive coral reefs are absent on the Seychelles, but individual corals and coralline algae are attached to granitic bedrock (Dutton et al., 2015b; Vyverberg et al., 2018) and found at high elevations, leading to an interpreted local sea level of around 

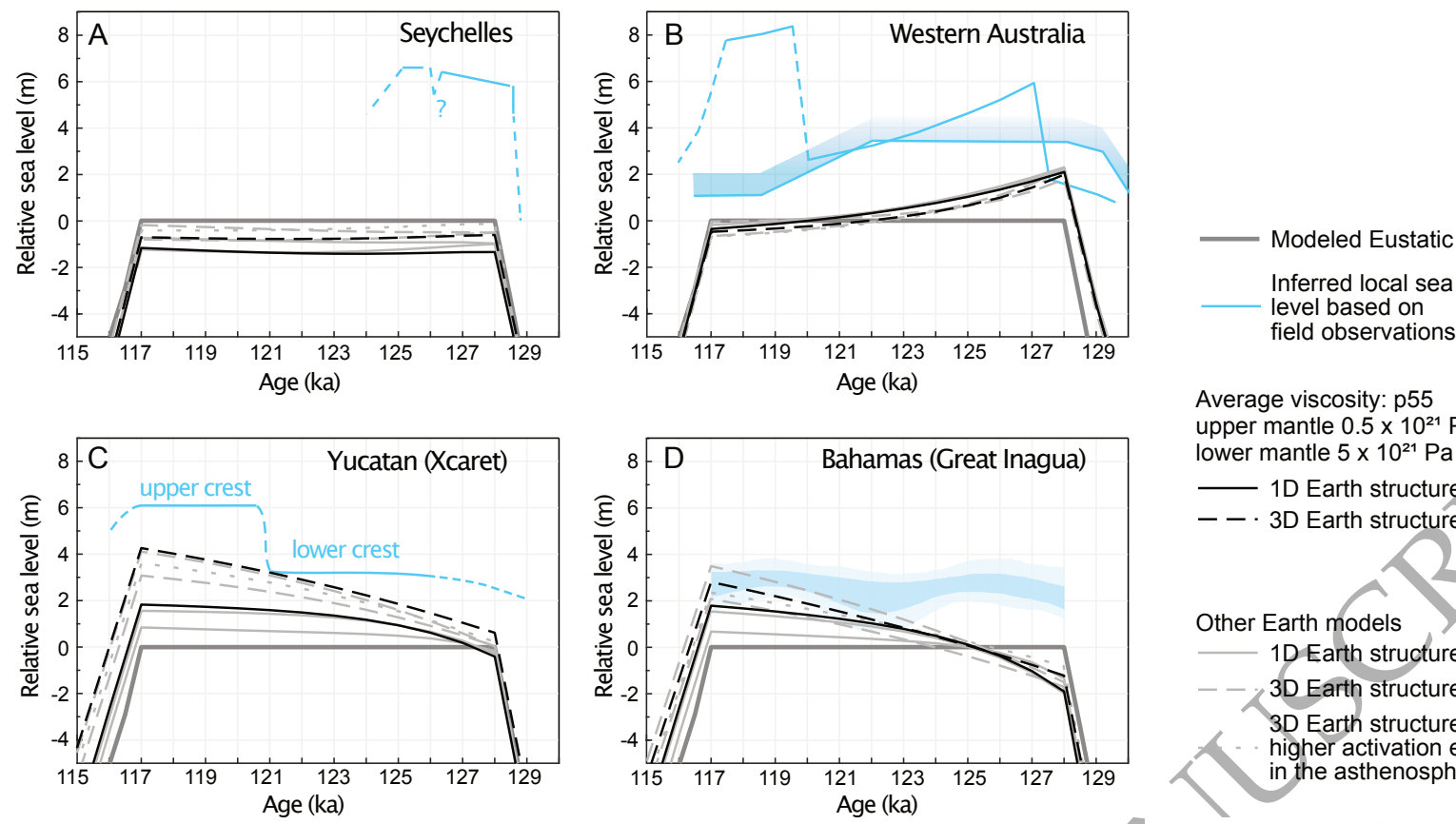
Average viscosity: p55
upper mantle $0.5 \times 10^{21} \mathrm{~Pa} \mathrm{~s}$
lower mantle $5 \times 10^{21} \mathrm{~Pa} \mathrm{~s}$

1D Earth structure

$--\cdot 3 \mathrm{D}$ Earth structure

Other Earth models 1D Earth structure 3D Earth structure

3D Earth structure higher activation energy in the asthenosphere
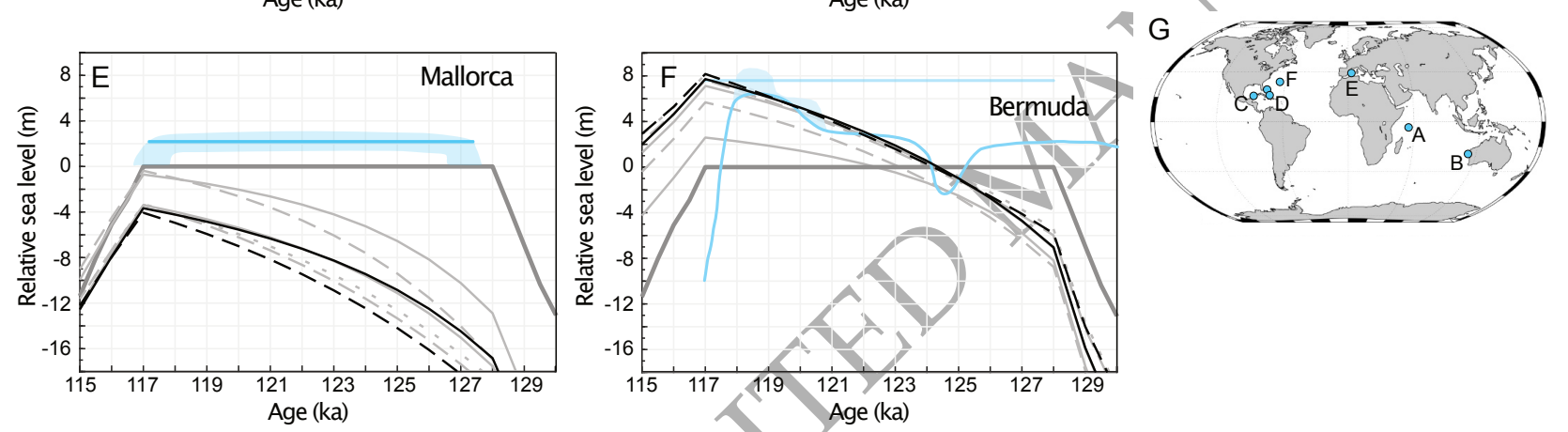

Figure 13: GIA time series at key sites withLIG sea-level records. A-F) Relative sea level at the Seychelles (La Digue), Western Australia (Cape Range), Yucatan Peninsula (Xcaret), Bahamas (Great Inagua and Eleuthera, Whale Point), Mallorca (Coves del Pirata), and Bermuda (Grape Bay), respectively. Thick grey line is the eustatic (global mean sea level) value assumed in the GIA model. Thus, any predicted relative sea-level change during the LIG is only due to GIA and not global mean sea-level changes. Black lines show predictions of relative sea level using a 1D (solid line) and the 3D (dashed line) GIA model with spherical average given by the p55 viscosity profile. Grey lines are results for different 1D and 3D Earth models from Fig. 8. Light blue lines show the inferred relative sea level at each site based on a variety of observations, with shaded regions marking uncertainties cited in the original publications: Seychelles (Dutton et al., 2015b); Western Australia, line without uncertainty (O'Leary et al., 2013) and line with uncertainty (Dutton \& Lambeck, 2012); Yucatan (Blanchon et al., 2009); Bahamas, with $1 \sigma$ and $2 \sigma$ uncertainty (Dyer et al., in press.); Mallorca (Polyak et al., 2018); and Bermuda, time-varying prediction (Hearty, 2002) and constant prediction based on the highest reported Devonshire marine member which has large age uncertainties (Muhs et al., 2020). G) Locations from A-F shown on a map. 
6- $7 \mathrm{~m}$ above present early in the LIG (Dutton et al., 2015b). 3D GIA results tend to increase the predicted relative sea level, which decreases the inferred GMSL (Fig. 13A). The magnitude of this effect ranges from 0 $1.5 \mathrm{~m}$ (where this range includes the simulation with a larger activation energy in the asthenosphere) leading to an inferred GMSL early in the LIG that remains larger than that at most other sites $(6-8.5 \mathrm{~m})$. Increasing the GIA prediction for local relative sea level (and hence reducing the inferred GMSL) is possible by decreasing the lithospheric thickness in this region (Fig. 7), which enhances continental levering. However, this effect would also be expected to occur during the Holocene and would result in an early Holocene sea-level highstand, which has not been observed (Woodroffe et al., 2015).

Inferences of GMSL during the LIG described above are based on a limited number of 3D simulations, and a rigorous analysis would require testing a significantly larger suite of Earth structures. In addition to Earth structure, there are several major uncertainties associated with the ice history that are not explored in this analysis, but will be briefly summarised: (1) The calculations performed here begin at $150 \mathrm{ka}$ (Fig. 1), which assumes that the ice-Earth system was in isostatic equilibrium at this time. We have performed 1D simulations that include earlier glacial cycles and found that this effect is on the order of $1 \mathrm{~m}$ in areas of the peripheral bulge and smaller (decimetre scale) in the far field; (2) GIA across the LIG will be sensitive to the specific ice sheet configuration adopted during the penultimate deglaciation, an uncertainty explored in detail elsewhere (Dendy et al., 2017; Rohling et al., 2017), and this factor will be particularly crucial to consider when attempting to reconcile relatively near-field sites such as Mallorca and Bermuda; (3) GIA predictions of relative sea level during the LIG are also sensitive to the ice history during the last glacial cycle (Lambeck et al., 2012). Here, we have assumed that sea level was relatively high during MIS 3 due to a small Laurentide ice sheet, following the results of Pico et al. (2017). If we were to assume that the Laurentide ice sheet was larger during MIS 3, it would lead to a further increase in predicted relative sea level during the LIG at sites close to the former Laurentide ice sheet; (4) Ice melt during the LIG will drive spatially variable sea level changes, and this should be accounted for when comparing GMSL inferences from different locations (Hay et al., 2014).

\section{Conclusion}

In this study we describe GIA predictions based on a new model of Earth's 3D viscoelastic structure inferred from recent global tomographic models (Schaeffer \& Lebedev, 2013, 2014; French \& Romanowicz, 2014). We use

an upper mantle anelastic parameterisation that relates shear wave speed to diffusion creep viscosity and is based 
on laboratory deformation experiments (Yamauchi \& Takei, 2016). The parameters within these relationships are calibrated such that the resulting temperature variations match a series of independent observables (Richards et al., 2020) and this reduces the uncertainty in the inferred viscosity. We note that the apparent viscosity over ice age timescales might deviate from the steady-state viscosity due to transient behaviour (Lau \& Holtzman, 2019), which is not explored here.

We use this new model of Earth's internal structure to produce the first estimates of GIA-driven sea-level change across the LIG that incorporate lateral variations in viscoelastic structure. We find that GIA predictions of relative sea level based on 3D versus 1D Earth structure have meter-scale differences in both the near and far field. We explore the mechanisms responsible for these differences and demonstrate how effects such as forebulge dynamics and continental levering are influenced by the presence of lateral variations in lithospheric thickness and underlying mantle viscosity. A more detailed examination of these differences is possible using 3D sensitivity kernels (Al-Attar \& Tromp, 2014; Crawford et al., 2018).

The effect that lateral viscosity variations have on sea level is weakly dependent on the globally averaged 1D viscosity structure that these variations are superimposed on: Using two different $1 \mathrm{D}$ profiles, we find that the difference between 3D and 1D predictions of LIG sea level differ more in magnitude than in geographic pattern. Thus, our results can be cautiously used as a first-order guide to whether lateral mantle viscosity variations might increase or decrease relative sea level in comparison to LD GIA predictions.

Given the computational expense of 3D GIA simulations, it is important to consider if and how well such simulations can be approximated by 1D GIA modelling. We find that 1D simulations that assume local Earth structure within a $3^{\circ}$ radius of the site do not produce results that are representative of the $3 \mathrm{D}$ result, which is consistent with earlier findings (Powell et al., 2019, Hartmann et al., 2020). However, a suite of 1D simulations suggests that a suitable and unique 1D approximation may exist for each site and we speculate that appropriate values for such a model might be found by averaging 3D structure over mantle regions characterised by high sensitivity (Crawford et al., 2018).

Lastly, we compare our predictions of GIA for 3D Earth models to local LIG sea-level reconstructions to investigate the implications of such models for estimates of GMSL during the LIG. It is noteworthy that lateral variations in mantle viscosity perturb predictions in a manner that may help to reconcile the mismatch in inferred GMSL early in the LIG from the Seychelles, where they lower this value, and Western Australia, where they increase it. However, this effect is not large enough to fully bring published estimates from these two sites into accord. Our results show that lateral variations in Earth structure are important to consider when reconstructing 
past sea level and estimating peak GMSL (or minimum ice volumes) during periods of relative ice age warmth.

\section{Acknowledgments}

This work has been supported by the National Science Foundation under grant OCE 18-41888 and ICER 19-28146 (JA) and OCE 17-02684 (JXM). MH and JXM acknowledge support from the National Aeronautics and Space Administration (grant NNX17AE17G). MH acknowledges support from the Australian government's Exploring for the Future program. FDR acknowledges support from the Schmidt Science Fellows program, in partnership with the Rhodes Trust, and the Imperial College Research Fellowship scheme. We are grateful to Tamara Pico for providing her ice reconstruction for MIS 3 to MIS 5d, Sia Ghelichkhan for discussions concerning conversion of seismic velocities into Earth structure, and Andrew Lloyd for discussions about sensitivity kernels and general feedback. The authors acknowledge PALSEA, a working group of the International Union for Quaternary Sciences (INQUA) and Past Global Changes (PAGES), which in turn received support from the Swiss Academy of Sciences and the Chinese Academy of Sciences.

\section{Author contributions}

JA designed the research and performed the sea-level analysis with input from all authors. MH and FDR performed conversions from shear wave speed to temperature and explored related uncertainties. KL performed the 3D GIA calculations and JA performed the 1D GIA calculations. JA and MH wrote the majority of the manuscript with input from all authors.

\section{Data availability}

The data underlying this article are available with the online version of this manuscript and in the accompanying OSF database (https://osf.io/m9qcz/). 


\section{References}

Al-Attar, D. \& Tromp, J., 2014. Sensitivity kernels for viscoelastic loading based on adjoint methods, Geophysical Journal International, 196(1), 34-77.

Andrault, D., Bolfan-Casanova, N., Nigro, G. L., Bouhifd, M. A., Garbarino, G., \& Mezouar, M., 2011. Solidus and liquidus profiles of chondritic mantle: Implication for melting of the Earth across its history, Earth and Planetary Science Letters, 304, 251-259.

Austermann, J., Mitrovica, J. X., Latychev, K., \& Milne, G. A., 2013. Barbados-based estimate of ice volume at Last Glacial Maximum affected by subducted plate, Nature Geoscience, 6(7), 553-557.

Austermann, J., Mitrovica, J. X., Huybers, P., \& Rovere, A., 2017. Detection of a dynamic topography signal in last interglacial sea-level records, Science Advances, 3(7), e1700457.

Barlow, N. L. M., McClymont, E. L., Whitehouse, P. L., Stokes, C. R., Jamieson, S. S. R., Woodroffe, S. A., Bentley, M. J., Callard, S. L., Cofaigh, C. Ó., Evans, D. J. A., Horrocks, J. R., Lloyd, J. M., Long, A. J., Margold, M., Roberts, D. H., \& Sanchez-Montes, M. L., 2018. Lack of evidence for a substantial sea-level fluctuation within the last interglacial, Nature Geoscience, 11(9), 627-634.

Blanchon, P., Eisenhauer, A., Fietzke, J., \& Liebetrau, V., 2009. Rapid sea-level rise and reef back-stepping at the close of the last interglacial highstand, Nature, 458(7240), 881-884.

Briggs, R. W., Engelhart, S. E., Nelson, A. R., Dura, T,, Kemp, A. C., Haeussler, P. J., Corbett, D. R., Angster, S. J., \& Bradley, L.-A., 2014. Uplift and subsidence reveal a nonpersistent megathrust rupture boundary (sitkinak island, alaska), Geophysical Research Letters, 41(7), 2289-2296.

Bullen, K. E., 1975. The Earth's density, Springer, London.

Cammarano, F., Goes, S., Vacher, P., \& Giardini, D., 2003. Inferring upper-mantle temperatures from seismic velocities, Physics of the Earth and Planetary Interiors, 138, 197-222.

Cathles, L. M., 1975. Viscosity of the Earth's mantle, Princeton University Press, Princeton.

Clark, P. U., He, F., Golledge, N. R., Mitrovica, J. X., Dutton, A., Hoffman, J. S., \& Dendy, S., 2020. Oceanic forcing of penultimate deglacial and last interglacial sea-level rise, Nature, 577(7792), 660-664. 
Colleoni, F., Wekerle, C., Näslund, J.-O., Brandefelt, J., \& Masina, S., 2016. Constraint on the penultimate glacial maximum northern hemisphere ice topography ( $\approx 140$ kyrs BP), Quaternary Science Reviews, 137, 97-112.

Connolly, J. A., 2005. Computation of phase equilibria by linear programming: A tool for geodynamic modeling and its application to subduction zone decarbonation, Earth and Planetary Science Letters, 236, 524-541.

Crawford, O., Al-Attar, D., Tromp, J., Mitrovica, J. X., Austermann, J., \& Lau, H. C. P., 2018. Quantifying the sensitivity of post-glacial sea level change to laterally varying viscosity, Geophysical Journal International, 214(2), 1324-1363.

Creveling, J. R., Mitrovica, J. X., Clark, P. U., Waelbroeck, C., \& Pico, T., 2017. Predicted bounds on peak global mean sea level during marine isotope stages 5a and 5c, Quaternary Science Reviews, 163, 193-208.

Dalton, C. A., Ekström, G., \& Dziewonski, A. M., 2009. Global seismological shear velocity and attenuation: A comparison with experimental observations, Earth and Planetary Science Letters, 284(1-2), 65-75.

Dannberg, J., Eilon, Z., Faul, U., Gassmöller, R., Moulik, P., \& Myhill, R., 2017. The importance of grain size to mantle dynamics and seismological observations, Geochemistry, Geophysics, Geosystems, 18(8), 3034-3061.

Debayle, E., Dubuffet, F., \& Durand, S., 2016. An automatically updated s-wave model of the upper mantle and the depth extent of azimuthal anisotropy, Geophysical Research Letters, 43(2), 674-682.

DeConto, R. M. \& Pollard, D., 2016. Contribution of antarctica to past and future sea-level rise, Nature, 531(7596), 591-597.

Dendy, S., Austermann, J., Creveling, J., \& Mitrovica, J., 2017. Sensitivity of last interglacial sea-level high stands to ice sheet configuration during marine isotope stage 6, Quaternary Science Reviews, 171, 234-244.

Dutton, A. \& Lambeck, K., 2012. Ice volume and sea level during the last interglacial, Science, 337(6091), $216-219$.

Dutton, A., Carlson, A. E., Long, A. J., Milne, G. A., Clark, P. U., DeConto, R., Horton, B. P., Rahmstorf, S., \& Raymo, M. E., 2015. Sea-level rise due to polar ice-sheet mass loss during past warm periods, Science, 349(6244), aaa4019-aaa4019. 
Dutton, A., Webster, J. M., Zwartz, D., Lambeck, K., \& Wohlfarth, B., 2015. Tropical tales of polar ice: evidence of last interglacial polar ice sheet retreat recorded by fossil reefs of the granitic seychelles islands, Quaternary Science Reviews, 107, 182-196.

Dyer, B., Austermann, J., DâĂŹAndrea, W. J., Creel, R. C., Sandstrom, M. R., Cashman, M., Rovere, A., \& Raymo, M. E., in press. Sea level trends across the bahamas constrain peak last interglacial ice melt, PNAS.

Dziewonski, A. M. \& Anderson, D. L., 1981. Preliminary reference Earth model, Physics of the Earth and Planetary Interiors, 25(4), 297-356.

Faul, U. \& Jackson, I., 2015. Transient Creep and Strain Energy Dissipation: An Experimental Perspective, Annual Review of Earth and Planetary Sciences, 43, 541-569.

Fei, H., Hegoda, C., Yamazaki, D., Wiedenbeck, M., Yurimoto, H., Shcheka, S., \& Katsura, T., 2012. High silicon self-diffusion coefficient in dry forsterite, Earth and Planetary Science Letters, 345-348, 95-103.

Fei, H., Wiedenbeck, M., Sakamoto, N., Yurimoto, H., Yoshino, T., Yamazaki, D., \& Katsura, T., 2018. Negative activation volume of oxygen self-diffusion in forsterite, Physics of the Earth and Planetary Interiors, 275, $1-8$.

Fichtner, A., Trampert, J., Cupillard, P., Saygin, E., Taymaz, T, Capdeville, Y., \& Villaseñor, A., 2013. Multiscale full waveform inversion, Geophysical Journal International, 194(1), 534-556.

Fischer, H., Meissner, K. J., Mix, A. C., Abram, N. J., Austermann, J., Brovkin, V., Capron, E., Colombaroli, D., Daniau, A.-L., Dyez, K. A., Felis, T., Finkelstein, S. A., Jaccard, S. L., McClymont, E. L., Rovere, A., Sutter, J., Wolff, E. W., Affolter, S., Bakker, P., Ballesteros-Cánovas, J. A., Barbante, C., Caley, T., Carlson, A. E., Churakova, O., Cortese, G., Curmming, B. F., Davis, B. A. S., de Vernal, A., Emile-Geay, J., Fritz, S. C., Gierz, P., Gottschalk, J., Holloway, M. D., Joos, F., Kucera, M., Loutre, M.-F., Lunt, D. J., Marcisz, K., Marlon, J. R., Martinez, P., Masson-Delmotte, V., Nehrbass-Ahles, C., Otto-Bliesner, B. L., Raible, C. C., Risebrobakken, B., Goñi, M. F. S., Arrigo, J. S., Sarnthein, M., Sjolte, J., Stocker, T. F., Alvárez, P. A. V., Tinner, W., Valdes, P. J., Vogel, H., Wanner, H., Yan, Q., Yu, Z., Ziegler, M., \& Zhou, L., 2018. Palaeoclimate constraints on the impact of $2^{\circ} \mathrm{c}$ anthropogenic warming and beyond, Nature Geoscience, 11(7), 474-485.

French, S. W. \& Romanowicz, B. A., 2014. Whole-mantle radially anisotropic shear velocity structure from spectral-element waveform tomography, Geophysical Journal International, 199(3), 1303-1327. 
Goldberg, S. L., Lau, H. C., Mitrovica, J. X., \& Latychev, K., 2016. The timing of the black sea flood event: Insights from modeling of glacial isostatic adjustment, Earth and Planetary Science Letters, 452, 178-184.

Gomez, N., Latychev, K., \& Pollard, D., 2018. A coupled ice sheet-sea level model incorporating 3D earth structure: Variations in antarctica during the last deglacial retreat, Journal of Climate, 31(10), 4041-4054.

Hartmann, R., Ebbing, J., \& Conrad, C., 2020. A multiple 1D earth approach (M1DEA) to account for lateral viscosity variations in solutions of the sea level equation: An application for glacial isostatic adjustment by antarctic deglaciation, Journal of Geodynamics, 135, 101695.

Hay, C., Mitrovica, J., Gomez, N., Creveling, J., Austermann, J., \& Kopp, R., 2014. The sea-level fingerprints of ice-sheet collapse during interglacial periods, Quaternary Science Reviews, 87, 60-69.

Hearty, P. J., 2002. Revision of the late pleistocene stratigraphy of bermuda, Sedimentary Geology, 153(1-2), $1-21$.

Hearty, P. J., Hollin, J. T., Neumann, A. C., O’Leary, M. J., \& McCulloch, M., 2007. Global sea-level fluctuations during the last interglaciation (MIS 5e), Quaternary Science Reviews, 26(17-18), 2090-2112.

Hirth, G. \& Kohlstedt, D., 2003. Rheology of the upper mantle and the mantle wedge: A view from the experimentalists, in Inside the Subduction Factory, pp. 83-105, American Geophysical Union.

Ho, T., Priestley, K., \& Debayle, E., 2016. A global horizontal shear velocity model of the upper mantle from multimode love wave measurements, Geophysical Journal International, 207(1), 542-561.

Hoggard, M. J., Winterbourne, J., Czarnota, K., \& White, N., 2017. Oceanic residual depth measurements, the plate cooling model, and global dynamic topography, Journal of Geophysical Research: Solid Earth, 122, $2328-2372$.

Hoggard, M. J., Czarnota, K., Richards, F. D., Huston, D. L., Jaques, A. L., \& Ghelichkhan, S., 2020. Global distribution of sediment-hosted metals controlled by craton edge stability, Nature Geoscience, 13.

Huang, P., Wu, P., \& Steffen, H., 2019. In search of an ice history that is consistent with composite rheology in glaeíal isostatic adjustment modelling, Earth and Planetary Science Letters, 517, 26-37.

Jackson, I. \& Faul, U. H., 2010. Grainsize-sensitive viscoelastic relaxation in olivine: Towards a robust 
laboratory-based model for seismological application, Physics of the Earth and Planetary Interiors, 183, $151-163$.

Jain, C., Korenaga, J., \& ichiro Karato, S., 2019. Global analysis of experimental data on the rheology of olivine aggregates, Journal of Geophysical Research: Solid Earth, 124(1), 310-334.

Karato, S., 1993. Importance of anelasticity in the interpretation of seismic tomography, Geophysical Research Letters, 20(15), 1623-1626.

Karato, S. \& Wu, P., 1993. Rheology of the upper mantle: A synthesis, Science, 260(5109), 771-778.

Kaufmann, G., Wu, P., \& Ivins, E. R., 2005. Lateral viscosity variations beneath antarctica and their implications on regional rebound motions and seismotectonics, Journal of Geodynamics, 39(2), 165-181.

Kendall, R. A., Mitrovica, J. X., \& Milne, G. A., 2005. On post-glacial sea level - II. numerical formulation and comparative results on spherically symmetric models, Geophysical Journal International, 161(3), 679-706.

Kopp, R. E., Simons, F. J., Mitrovica, J. X., Maloof, A. C., \& Oppenheimer, M., 2009. Probabilistic assessment of sea level during the last interglacial stage, Nature, 462(7275), 863-867.

Kuchar, J., Milne, G., \& Latychev, K., 2019. The importance oflateral earth structure for north american glacial isostatic adjustment, Earth and Planetary Science Letters, 512, 236-245.

Kustowski, B., Ekström, G., \& Dziewoński, A. M., 2008. Anisotropic shear-wave velocity structure of the earth's mantle: A global model, Journal of Geophysical Research, 113(B6).

Lambeck, K., Purcell, A., Funder, S., Kjær, K., Larsen, E., \& Möller, P., 2006. Constraints on the late saalian to early middle weichselian ice sheet of eurasia from field data and rebound modelling, Boreas, 35(3), 539-575.

Lambeck, K., Purcell, A., \& Dutton, A., 2012. The anatomy of interglacial sea levels: The relationship between sea levels and ice volumes during the last interglacial, Earth and Planetary Science Letters, 315-316, 4-11.

Latychev, K., Mitrovica, J. X., Tromp, J., Tamisiea, M. E., Komatitsch, D., \& Christara, C. C., 2005. Glacial isostatic adjustment on 3-d earth models: a finite-volume formulation, Geophysical Journal International, 161(2), $421-444$. 
Lau, H. C. P. \& Holtzman, B. K., 2019. "measures of dissipation in viscoelastic media” extended: Toward continuous characterization across very broad geophysical time scales, Geophysical Research Letters, 46(16), 9544-9553.

Lau, H. C. P., Mitrovica, J. X., Austermann, J., Crawford, O., Al-Attar, D., \& Latychev, K., 2016. Inferences of mantle viscosity based on ice age data sets: Radial structure, Journal of Geophysical Research: Solid Earth, 121(10), 6991-7012.

Lau, H. C. P., Holtzman, B. K., \& Havlin, C., 2020. Toward a self-consistent characterization of lithospheric plates using full-spectrum viscoelasticity, $A G U$ Advances, 1(4).

Li, T., Wu, P., Steffen, H., \& Wang, H., 2018. In search of laterally heterogeneous viscosity models of glacial isostatic adjustment with the ICE-6g_c global ice history model, Geophysical Journal International, 214(2), $1191-1205$.

McCarthy, C., Takei, Y., \& Hiraga, T., 2011. Experimental study of attenuation and dispersion over a broad frequency range: 2. The universal scaling of polycrystalline materials, Journal of Geophysical Research, 116(B09207).

Mitrovica, J. \& Milne, G., 2002. On the origin of late holocene sea-level highstands within equatorial ocean basins, Quaternary Science Reviews, 21(20-22), 2179-2190.

Mitrovica, J. X. \& Milne, G. A., 2003. On post-glacial sea level: I. general theory, Geophysical Journal International, 154(2), 253-267.

Muhs, D. R., Simmons, K. R., Schumann, R. R., Schweig, E. S., \& Rowe, M. P., 2020. Testing glacial isostatic adjustment models of last-interglacial sea level history in the bahamas and bermuda, Quaternary Science Reviews, 233, 106212.

Nield, G. A., Whitehouse, P. L., van der Wal, W., Blank, B., O'Donnell, J. P., \& Stuart, G. W., 2018. The impact of lateral variations in lithospheric thickness on glacial isostatic adjustment in west antarctica, Geophysical Journal/nternational, 214(2), 811-824.

O’Leary, M. J., Hearty, P. J., Thompson, W. G., Raymo, M. E., Mitrovica, J. X., \& Webster, J. M., 2013. Ice sheet collapse following a prolonged period of stable sea level during the last interglacial, Nature Geoscience, 6(9), 796-800. 
Peltier, W. R., Argus, D. F., \& Drummond, R., 2015. Space geodesy constrains ice age terminal deglaciation: The global ICE-6g_c (VM5a) model, Journal of Geophysical Research: Solid Earth, 120(1), 450-487.

Pico, T., 2019. Towards assessing the influence of sediment loading on last interglacial sea level, Geophysical Journal International, 220(1), 384-392.

Pico, T., Creveling, J. R., \& Mitrovica, J. X., 2017. Sea-level records from the u.s. mid-atlantic constrain laurentide ice sheet extent during marine isotope stage 3, Nature Communications, $8(1)$.

Polyak, V. J., Onac, B. P., Fornós, J. J., Hay, C., Asmerom, Y., Dorale, J. A., Ginés, J., Tuccimei, P., \& Ginés, A., 2018. A highly resolved record of relative sea level in the western mediterranean sea during the last interglacial period, Nature Geoscience, 11(11), 860-864.

Powell, E., Gomez, N., Hay, C., Latychev, K., \& Mitrovica, J. X., 2019. Viscous effects in the solid earth response to modern antarctic ice mass flux: Implications for geodetic studies of WAIS stability in a warming world, Journal of Climate, 33(2), 443-459.

Priestley, K., McKenzie, D., \& Ho, T., 2018. A lithosphere-asthenosphere boundary-a global model derived from multimode surface-wave tomography and petrology.

Ranalli, G., 1995. Rheology of the Earth, Springer, London, 2nd edn.

Raymo, M. E. \& Mitrovica, J. X., 2012. Collapse of polar ice sheets during the stage 11 interglacial, Nature, 483(7390), 453-456.

Raymo, M. E., Mitrovica, J. X., O’Leary, M. J., DeConto, R. M., \& Hearty, P. J., 2011. Departures from eustasy in pliocene sea-level records, Nature Geoscience, 4(5), 328-332.

Richards, F. D., Hoggard, M. J., Cowton, L. R., \& White, N. J., 2018. Reassessing the thermal structure of oceanic lithosphere with revised global inventories of basement depths and heat flow measurements, Journal of Geophysical Research: Solid Earth, 123, 9136-9161.

Richards, F.D., Hoggard, M. J., White, N. J., \& Ghelichkhan, S., 2020. Quantifying the relationship between short-wavelength dynamic topography and thermomechanical structure of the upper mantle using calibrated parameterization of anelasticity, Journal of Geophysical Research: Solid Earth. 
Rohling, E. J., Hibbert, F. D., Williams, F. H., Grant, K. M., Marino, G., Foster, G. L., Hennekam, R., de Lange, G. J., Roberts, A. P., Yu, J., Webster, J. M., \& Yokoyama, Y., 2017. Differences between the last two glacial maxima and implications for ice-sheet, $\delta 180$, and sea-level reconstructions, Quaternary Science Reviews, 176, 1-28.

Rovere, A., Raymo, M. E., Vacchi, M., Lorscheid, T., Stocchi, P., Gómez-Pujol, L., Harris, D. L., Casella, E., O'Leary, M. J., \& Hearty, P. J., 2016. The analysis of last interglacial (MIS 5e) relative sea-level indicators: Reconstructing sea-level in a warmer world, Earth-Science Reviews, 159, 404-427.

Rowley, D. B., Forte, A. M., Moucha, R., Mitrovica, J. X., Simmons, N. A., \& Grand, S. P., 2013. Dynamic topography change of the eastern united states since 3 million years ago, Science, 340(6140), 1560-1563.

Sandstrom, M. R., O’Leary, M. J., Barham, M., Cai, Y., Rasbury, E. T., Wooton, K. M., \& Raymo, M. E., 2020. Age constraints on surface deformation recorded by fossil shorelines at cape range, western australia, GSA Bulletin.

Schaeffer, A. J. \& Lebedev, S., 2013. Global shear speed structure of the upper mantle and transition zone, Geophysical Journal International, 194, 417-449.

Schaeffer, A. J. \& Lebedev, S., 2014. Imaging the North American continent using waveform inversion of global and USArray data, Earth and Planetary Science Letters, 402, 26-41.

Schuberth, B. S. A. \& Bunge, H. P., 2009. Tomographic filtering of high-resolution mantle circulation models: Can seismic heterogeneity be explained by temperature alone?, Geochemistry, Geophysics, Geosystems, 10(5).

Shakun, J. D., Lea, D. W., Lisiecki, L. E., \& Raymo, M. E., 2015. An 800-kyr record of global surface ocean $\delta 180$ and implications for ice volume-temperature coupling, Earth and Planetary Science Letters, 426, 58-68.

Skrivanek, A., Li, J., \& Dutton, A., 2018. Relative sea-level change during the last interglacial as recorded in bahamian fossil reefs, Quaternary Science Reviews, 200, 160-177.

Steinberger, B., 2016. Topography caused by mantle density variations: Observation-based estimates and models derived from tomography and lithosphere thickness, Geophysical Journal International, 205, 604-621. 
Steinberger, B. \& Calderwood, A. R., 2006. Models of large-scale viscous flow in the Earth's mantle with constraints from mineral physics and surface observations, Geophysical Journal International, 167, 14611481.

Stephenson, S. N., White, N. J., Li, T., \& Robinson, L. F., 2019. Disentangling interglacial sea level and global dynamic topography: Analysis of madagascar, Earth and Planetary Science Letters, 519, 61-69.

Stixrude, L. \& Lithgow-Bertelloni, C., 2011. Thermodynamics of mantle minerals - II. Phase equilibria, Geophysical Journal International, 184, 1180-1213.

Sundberg, M. \& Cooper, R. F., 2010. A composite viscoelastic model for incorporating grain boundary sliding and transient diffusion creep: Correlating creep and attenuation responses for materials with a fine grain size, Philosophical Magazine, 90(20), 2817-2840.

Takei, Y., 2017. Effects of partial melting on seismic velocity and attenuation: A new insight from experiments, Annual Review of Earth and Planetary Sciences, 45, 447-470.

Thomas, A. L., Henderson, G. M., Deschamps, P., Yokoyama, Y., Mason, A. J., Bard, E., Hamelin, B., Durand, N., \& Camoin, G., 2009. Penultimate deglacial sea-level timing from uranium/thorium dating of tahitian corals, Science, 324(5931), 1186-1189.

Turcotte, D. L. \& Schubert, G., 2002. Geodynamics, Cambridge University Press, Cambridge, 2nd edn.

van der Wal, W., Wu, P., Wang, H., \& Sideris, M. G., 2010. Sea levels and uplift rate from composite rheology in glacial isostatic adjustment modeling, Journal of Geodynamics, 50(1), 38-48.

van der Wal, W., Barnhoorn, A., Stocchi, P., Gradmann, S., Wu, P., Drury, M., \& Vermeersen, B., 2013. Glacial isostatic adjustment model with composite 3-d earth rheology for fennoscandia, Geophysical Journal International, 194(1), 61-77.

van Hinsbergen, D.J., Vissers, R. L., \& Spakman, W., 2014. Origin and consequences of western Mediterranean subduction, rollback, and slab segmentation, Tectonics, 33, 393-419.

Vyverberg, K., Dechnik, B., Dutton, A., Webster, J. M., Zwartz, D., \& Portell, R. W., 2018. Episodic reef growth in the granitic seychelles during the last interglacial: Implications for polar ice sheet dynamics, Marine Geology, 399, 170-187. 
Waelbroeck, C., Labeyrie, L., Michel, E., Duplessy, J. C., \& Mcmanus, J. F., 2002. Sea-level and deep water temperature changes derived from benthic foraminifera isotopic records, Quaternary Science Reviews, 21, $295-305$.

Watts, A., Zhong, S., \& Hunter, J., 2013. The behavior of the lithosphere on seismic to geologic timescales, Annual Review of Earth and Planetary Sciences, 41(1), 443-468.

Woodroffe, S. A., Long, A. J., Milne, G. A., Bryant, C. L., \& Thomas, A. L., 2015. New constraints on late holocene eustatic sea-level changes from mahé, seychelles, Quaternary Science Reviews, 115, 1-16.

Wu, P., Wang, H., \& Steffen, H., 2012. The role of thermal effect on mantle seismic anomalies under laurentia and fennoscandia from observations of glacial isostatic adjustment, Geophysical Journal International, 192(1), $7-17$.

Yamauchi, H. \& Takei, Y., 2016. Polycrystal anelasticity at near-solidus temperaturés, Journal of Geophysical Research: Solid Earth, 121(11), 7790-7820. 


\section{Appendix A: Anelastic parameterisation}

The anelastic parameterisation of Yamauchi \& Takei (2016) represents linear viscoelasticity in the frequency domain using a complex compliance, the real component of which refers to the amplitude of strain that occurs in phase with the driving stress and the imaginary component refers to strain that is $\pi / 2$ radians out of phase (and gives rise to dissipation). Processes responsible for accommodating anelastic deformation are represented using a relaxation spectrum that consists of a high-frequency peak superimposed on top of a monotonic background. The height and width of the high-frequency peak is a function of the material's homologous temperature, $\frac{T}{T_{m}}$. The background takes advantage of the Maxwell frequency "master variable" scaling results of McCarthy et al. (2011), which crucially showed that the effects of variations in composition, grain size, and temperature on attenuation can be accurately predicted using the corresponding effect of these parameters on the steady-state diffusion creep viscosity of the material.

In their laboratory experiments on organic rock-analogues, Yamauchi \& Takei (2016) were able to ascertain the values of several anelastic parameters that are thought to be consistent between different polyscrystalline materials (e.g. the centre frequency of the relaxation peak). Seven other parameters are specific to each individual material and need to be independently determined. These include the unrelaxed shear modulus at reference conditions, its dependence on temperature and pressure, the viscosity at reference conditions $\left(1200^{\circ} \mathrm{C}\right.$ and $\left.1.5 \mathrm{GPa}\right)$, its dependence on temperature and pressure (activation energy and activation volume, respectively), and the solidus gradient. Assuming that suitable values for these parameters can be ascertained, the parameterisation allows shear wave velocities to be converted into temperature and steady-state diffusion creep viscosity in a self-consistent manner. The exact form used in this study is given by Equations (3) - (17) of Richards et al. (2020). 